\title{
Análise da Influência do Fluxo de Caixa Livre nos Indicadores de Desempenho Econômico em Companhias Abertas Brasileiras
}

\section{Analysis of Free Cash Flow Influence on Economic Performance Indicators in Brazilian Public Companies}

\author{
Arthur Frederico Lerner Mestre em Controladoria e Contabilidade. Universidade Federal do Rio Grande do Sul (UFRGS) - \\ Brasil.arthurlerner_@hotmail.com \\ Fernanda Gomes Victor Doutora em Administração - Finanças. Universidade Federal do Rio Grande do Sul (UFRGS) - \\ Brasil. fernanda.g.victor@gmail.com
}

\section{RESUMO}

Esse estudo visa investigar a relação do Fluxo de Caixa Livre (FCL) com o desempenho econômico das companhias abertas listadas na Brasil, Bolsa, Balcão $[B]^{3}$. Para tanto, verificou-se a influência do $F C L$ nos Indicadores de Desempenho Econômico (IDE) destas companhias, utilizando-se diversas variáveis para os testes. Trata-se de uma pesquisa quantitativa, descritiva e documental. O período analisado foi de 2009 a 2017, com dados trimestrais, coletados na base Economática , totalizando uma amostra de 5.292 observações empresa-ano e 147 companhias. Para responder ao problema de pesquisa, foram realizadas estimações por Mínimos Quadrados Ordinários (MQO) e via regressão quantílica com dados em painel balanceado. As métricas de FCL calculadas apresentaram estatísticas diferentes entre si, o que corrobora o fato dessa medida ser arbitrária e ao mesmo tempo subjetiva. Os resultados das regressões também foram diferentes para cada medida. Sendo assim, não se desconsidera a possibilidade de o FCL influenciar os IDE das companhias abertas brasileiras, sendo os sinais dos coeficientes relativos para cada variável. Não obstante, os achados das regressões quantílicas apontam problemas de agência nas companhias listadas na $[B]^{3}$, pois sua sensibilidade aumenta nos maiores quantis. Consequentemente, a Teoria do Free Cash Flow não pode ser rejeitada no mercado brasileiro.

Palavras-chave: Fluxo de caixa livre. Teoria do Free Cash Flow. Custos de agência. Indicadores de desempenho econômico.

\section{ABSTRACT}

This study aims to investigate the relationship between Free Cash Flow (FCF) and the economic performance of publicly-held companies listed in Brazil, Bolsa, Balcão $[B]^{3}$. To this end, the influence of FCF on the Economic Performance Indicators (EPI) of these companies was verified, using several variables for the tests. It is a quantitative, descriptive and documentary research. The period analyzed was from 2009 to 2017, with quarterly data, collected on the basis of Economática', totaling a sample of 5,292 company-year observations and 147 companies. To answer the research problem, estimations were made using Ordinary Least Squares (OLS) and via quantile regression with balanced panel data. The calculated FCF metrics presented different statistics, which corroborates the fact that this measure is arbitrary and at the same time subjective. The results of the regressions were also different for each measure. Therefore, the possibility of FCF influencing the EPI of Brazilian public companies is not disregarded, being the signs of the coefficients relative for each variable. Nevertheless, the findings of quantile regressions point to agency problems in the companies listed in $[B]^{3}$, as their sensitivity increases at the highest quantiles. Consequently, the Free Cash Flow Theory cannot be rejected in the Brazilian market.

Keywords: Free cash flow. Free Cash Flow Theory. Agency costs. Economic performance indicators. 


\section{INTRODUÇÃO}

O estudo de Jensen e Meckling (1976) expôs a relação na qual uma ou mais pessoas (principal) contratam outra pessoa (agente) para executar algum serviço em seu nome, que envolve delegar alguma autoridade de tomada de decisão. Contudo, nem sempre o agente vai atender os interesses do principal da melhor maneira possível, configurando a Teoria da Agência.

Os problemas de agência causados pela administração agravam a perda do acionista (WANG, 2010). Contudo, Jensen e Meckling (1976) não deixaram claro como eles eram definidos e medidos. Jensen (1986a, 1986b, 1988) vinculou a Teoria da Agência ao Fluxo de Caixa Livre (FCL ou Free Cash Flowdo inglês) [Teoria do Free Cash Flow], de tal forma que a administração, agindo por interesses próprios, poderia abusar dos recursos sob sua autoridade, quando as oportunidades de investimento não estavam prontamente disponíveis para a empresa. Portanto, o excesso de FCL nas mãos da administração é custo de agência para os acionistas, de forma que impacta negativamente no desempenho econômico das companhias.

Nesse sentido, o conflito de interesses vinculadoa grandes quantias de $\mathrm{FCL}$ geraria uma maior tendência dos gestores a realizarem investimentos ineficazes ou negativos. Assim, a questão-chave da pesquisa é se o excedente de $F C L$ poderia ser não benéfico para as empresas, aumentando seus custos de agência e diminuindo seu desempenho econômico futuro. Porém, um dos problemas enfrentados pelos estudiosos da área é mensurar com confiabilidade quando o FCL é exagerado, levando em consideração as particularidades de cada companhia.

No contexto internacional, os estudos de Hong, Shuting e Meng (2012), Mansourlakoraj e Sepasi (2015), Moussavi et al. (2015), Najmi, Sarraf e Darabi (2015), Hau (2017) e Kadioglu, Kilic e Yilmaz (2017) analisaram a relação do $\mathrm{FCL}$ com Indicadores de Desempenho Econômico (IDE) empresariais na expectativa de obter evidências da Teoria do Free Cash Flow. Entretanto, não encontraram relações convergentes devido ao fato que cada pesquisa utilizou indicadores e medidas de FCL diferentes. Sendoassim,selecionaram-se três IDE (ROA, Market-to-book e $q$ de Tobin), duasmedições de FCL e, em diferentes regressões, comparou-se seu comportamento.

Muitos usuários das demonstrações contábeis acreditam que o FCL é uma importante medida em seus processos de tomada de decisão (KETZ, 2016), visto que diariamente surgem notícias que dão conta de que organizações são compradas e vendidas por valores absolutamente distintos daqueles refletidos pelo seu patrimônio líquido contábil. No mercado, onde essas informações impactam, percebem-se algumas contradições/preocupações dos profissionais em relação ao tema. Como por exemplo, não é incomum que os investidores busquem empresas com $\mathrm{FCL}$ em rápido aumento, uma vez que essas podem ter excelentes perspectivas de futuro, ou seja, se o FCL é crescente e o preço da ação está subavaliado, pode ser uma excelente aposta de investimento. Contudo, há, também, a possibilidade de os gerentes usarem práticas contábeis, como o gerenciamento de resultados, que manipulem, massifiquem ou suavizem os ganhos reportados para ofuscar ou camuflar os efeitos dos maus investimentos (CHUNG; FIRTH; KIM, 2005).

Nesse contexto, existem essas duas suposições conflitantes sobre o FCL, para uma delas, quanto maior - FCL melhor para a empresa, para outra, quanto maior o FCL pior para companhia. Porém, estas suposições vão depender de outras diversas variáveis, tais como as oportunidades de crescimento apontadas por Jensen (1986a, 1986b, 1988), por exemplo. Além disso, Mills, Bible e Mason (2002) listam doze diferentes definições de FCL em uso por empresas, revistas, livros didáticos e editores de informações financeiras. O que torna a sua mensuração alvo de discussões. Diante do exposto, surge a questão que motiva a presente pesquisa: qual é a influênciado Fluxo de Caixa Livre (FCL) nos Indicadores de Desempenho Econômico (IDE) das companhias abertas brasileiras da Brasil, Bolsa, Balcão [B] de 2009 a 2017?

A verificação desse problema de pesquisa tem como base as principais teorias sobre o tema e artigos empíricos internacionais, visto que não foram encontrados estudos nacionais, tampouco modelos econométricos idênticos ao utilizado. Assim, esta pesquisa propõe-se a verificar se o FCL exerce influência de forma significativa sobre os IDE das companhias abertas brasileiras listadas na [B] $]^{3}$.

No estudo de Moussavi et al. (2015), por exemplo, foi analisado se o FCL possui relação com IDE compondo uma amostra de 406 companhias listadas na Bolsa de Valores de Teerã (Irã) no período de 2008 a 
2015. O estudo obteve indícios de que o FCL possui relação positiva e significativa com o Valor de Mercado Adicionado (será referido pelo termo MVA, do inglês Market Value Added) e com o Lucro Antes dos Juros e Tributos (será referido pelo termo EBIT, do inglês Earnings Before Interest and Taxes), em oposição à teoria. Os resultados não apontaram evidências suficientes para que a Teoria do Free Cash Flow seja confirmada no mercado iraniano. Os próprios autores ressaltam a carência de pesquisas semelhantes para comparar seus resultados, mesmo no âmbito internacional.

Entre as principais contribuições deste estudo destacam-se: i) fornecer evidências sobre a Teoria do Free Cash Flow no contexto nacional; ii) fornecer evidências empíricas sobre os impactos do FCL nos IDE no Brasil e o grau de importância que essas informações possuem aos investidores; e iii) contribuir para a literatura do FCL e IDE.

As evidências empíricas obtidas podem contribuir para estabelecer políticas de gestão mais eficazes e maximizar a riqueza das companhias, visto que se busca refletir um conjunto de fatos por meio da observação direta da realidade. Além disso, otimizar o uso dos recursos das companhias e minimizar os seus custos é um interesse indiscutível de investidores e credores das empresas, e resulta em benefícios para toda a sociedade.

\section{REFERENCIAL TEÓRICO}

Essa seção discorre primeiramente sobre os conceitos e formas de mensuração do FCL e sua relação com a Teoria da Agência. Por fim, apresenta os estudos relacionados e a construção da hipótese de pesquisa.

\subsection{Conceito e formas de mensuração do Fluxo de Caixa Livre}

Existem várias formas de definir o $\mathrm{FCL}$, o que pode resultar em problemas de consistência e comparabilidade entre companhias. Na visão de Martelanc, Pasin e Pereira (2010) o FCL traz um conceito semelhante ao Lucro Líquido, só que em regime de caixa e não de competência. Brigham e Ehrhardt (2016, p. 57) definem o FCL como "[...] o fluxo de caixa disponível para distribuição a todos os investidores da empresa depois que ela fez todos os investimentos necessários para sustentar as operações em curso.".

Na concepção de Jensen (1986a), os administradores com grandes quantias de FCL podem aumentar o montante de dividendos pagos ou recomprar ações e, assim, evitar que o dinheiro seja investido em projetos de baixo retorno ou desperdiçado. Ter uma folga financeira (caixa disponível) pode ser um elemento constitutivo da Teoria do Free Cash Flow. Como afirmam Brealey, Myers e Allen (2008), uma folga financeira excessiva pode encorajar os administradores a diminuir o ritmo, aumentar seus benefícios, sua remuneração ou até a construir "impérios" com o dinheiro que supostamente deveria ser pago aos acionistas.

Dentro da mesma perspectiva, Kester (1986) e Gul e Tsui (1998) argumentaram que a administração estando sujeita à vinculação legal de pagamento de dívida e juros, pode diminuir o abuso do FCL. A ameaça causada pela falta de pagamento da dívida serve como uma força motivadora efetiva para tornar as organizações mais eficientes, assim, a dívida reduz os custos da agência do FCL (JENSEN, 1986a).

Assim, uma forma de controlar os gestores é forçá-los a tomarem empréstimos, uma vez que os financiamentos criam compromissos de efetuar pagamentos, aumentando o risco de inadimplência de projetos com retornos abaixo do padrão (DAMODARAN, 2002). Brealey, Myers e Allen (2008) consideram que o endividamento força a empresa a desembolsar fundos e tende a disciplinar os administradores a ficarem atentos a não investir demais, também serve como uma forma impor melhorias na eficiência operacional. Em contrapartida, Lehn e Poulsen (1989), Fox e Marcus (1992), Jensen (1993) e Dial e Murphy (1995) sugeriram uma abordagem encorajadora em que a empresa poderia mudar a postura da administração para ser mais favorável aos acionistas, aumentando a parcela de ações dos gestores. À medida que a proporção de participação acionária gerencial aumenta, o mesmo acontece com o desempenho corporativo (JENSEN, 1993).

Embora o endividamento seja uma solução, Damodaran (2002) explica que a dívida pode ter efeito benéfico até certo ponto, pois em algum momento o risco resultante da alavancagem pode ser tão alto que os gestores podem vir a se tornarem relutantes em assumir os riscos mais insignificantes, por medo de falência, 
e deixarem de investir em bons projetos. A proporção adequada de dívida e caixa (dinheiro disponível) individual de cada empresa é o ponto em que seu valor é maximizado (JENSEN, 1986a). Tomar recursos emprestados em excesso pode expor a companhia à inadimplência se os fluxos de caixa das operações forem insuficientes para pagar os juros, podendo levar a uma eventual liquidação (DAMODARAN, 2004).

Assim, para Jensen (1986a), as companhias com poder de empréstimo não utilizado e grandes proporções de FCL são propensas a adotar uma estratégia de crescimento que destrói o valor da empresa, crescendo sem criar qualquer valor para o acionista. Para o autor, a função de controle da dívida é mais importante em organizações que geram grandes $\mathrm{FCL}$, mas apresentam baixas perspectivas de crescimento. Nessas organizações, as possibilidades de desperdiçar os fluxos de caixa investindo-os em projetos não rentáveis são maiores.

Empresas com grandes FCL e oportunidades de crescimento limitadas são mais propensas a realizar aquisições que não criam valor para o acionista (ATAÜNAL; AYBARS, 2017). Em contrapartida, as empresas com mais oportunidades de investimento usam sua geração de caixa interna de forma mais produtiva (DOUKAS, 1995). Na análise empírica de Stulz (1990), em particular, os acionistas de uma empresa com FCL negativo e poucas oportunidades de investimento podem querer que a empresa emita dívidas para que a administração controle ainda menos recursos, enquanto os acionistas de uma empresa com FCL positivo e boas oportunidades de investimento podem querer que a gestão aumente ainda mais os fundos para diminuir a probabilidade de que alguma oportunidade positiva seja inexplorada. $O$ autor sugere que a diversificação de investimentos reduz os custos da agência porque torna o fluxo de caixa mais previsível.

$\mathrm{Na}$ visão dos analistas de mercado, uma empresa com FCL crescente ao longo dos anos geralmente está indo bem e pode querer considerar expansão, enquanto uma companhia com FCL regressivo ao longo do tempo pode precisar se reestruturar. Para Moussavi et al. (2015), cada empresa possui um nível adequado entre o custo de oportunidade de retenção de caixa e o custo de saldo insuficiente de caixa. Ou seja, mantendo muito dinheiro em caixa a companhia está deixando de investir e consequentemente aumentar o resultado futuro, mas aplicando os recursos de forma demasiada corre o risco de ficar inadimplente com os credores.

Uma vez calculado o valor do FCL, pode-se projetá-lo no tempo em um horizonte estabelecido pelo analista, de forma a obter os rendimentos futuros estimados, que posteriormente serão descontados a termos presentes, de forma a estimar o valor da empresa em análise (STOWE et al., 2007).

Para alguns profissionais, o FCL é apenas outra métrica, não diz tudo, nem será útil para todos os tipos de empresas, mas observar que há uma diferença grande entre o Lucro Líquido e o FCL certamente será um incremento na análise do investidor. No estudo de Hong, Shuting e Meng (2012), os resultados empíricos mostram que o FCL e os índices de desempenho financeiro consolidados têm uma correlação negativa e significativa, indicando que o fluxo de caixa excedente não é propício para o desempenho financeiro das empresas.

\subsection{Estudos relacionados}

As pesquisas de Chung, Firth e Kim (2005), Wang (2010) e Hau (2017), evidenciaram que o FCL tem um impacto positivo no desempenho da empresa, medido pelo ROA [Return on Assets]. Wang (2010) encontrou relação positiva entre o FCL e o ROE [Return on Equity], por outro lado, Moussavi et al. (2015) também testou a dependência das variáveis, mas não encontrou significância.

Pesquisadores como Chung, Firth e Kim (2005), Wang (2010), Mansourlakoraj e Sepasi (2015), Najmi, Sarraf e Darabi (2015) e Kadioglu, Kilic e Yilmaz (2017) testaram o valor e/ou desempenho da empresa por meio do $q$ de Tobin. Os resultados mostraram que o FCL impacta positivamente o $q$ de Tobin, contrariando a Teoria do Free Cash Flow. O único estudo que evidenciou uma relação negativa entre FCL e $q$ de Tobin foi o de Kadioglu, Kilic e Yilmaz (2017).

Moussavi et al. (2015) se propuseram a investigar se o FCL teria relação com indicadores de desempenho, por meio de uma regressão simples para cada indicador. As variáveis testadas foram EBIT, MVA, Market-to-Book, ROE e Qualidade dos Ganhos (Earnings Quality). Os resultados evidenciaram correlação significativa e positiva apenas entre o FCL com EBIT e FCL com MVA. A falta de estudos similares é apontada 
pelos autores. A partir da revisão de literatura acerca do conceito de $\mathrm{FCL}$, e das pesquisas relacionadas anteriormente citadas, foi possível identificar que existem diferentes formas de mensurar o FCL.

Percebe-se que as pesquisas que envolveram o FCL definiram, mediram e executaram análises empíricas para apoiarem suas hipóteses, no entanto a maioria tinha suas próprias métricas de FCL. Constatouse também que outros pesquisadores simplesmente inseriram FCL no título de seus artigos, mas não o definiram nem o mediram, muito menos o usaram em suas análises empíricas, o que foi verificado também por Bhandari e Adams (2017).

Nas pesquisas de Lang, Stulz e Walking (1991), Gul e Tsui (1998) e Chung, Firth e Kim (2005), os autores utilizaram mais de uma medida de FCL com a intenção de dar maior robustez aos resultados. $\mathrm{O}$ estudo de Richardson (2006), propôs uma proxy para mensurar as despesas esperadas com novos investimentos, relacionado-a com o FCL. O mesmo fizeram os seus sucessores Cai (2014), Najmi, Sarraf e Darabi (2015), Chen, Sun e Xu (2016) e Jiang (2016).

No intento de avaliar a partir de qual variável o FCL é mensurado, ou seja, o ponto de partida, verificase que Lehn e Poulsen (1989), Lang, Stulz e Walking (1991), Gul e Tsui (1998) e Mansourlakoraj e Sepasi (2015) desenvolvem seus cálculos do EBITDA [Earnings Before Interest, Taxes, Depreciation and Amortization]. Hau (2017) e Kadioglu, Kilic e Yilmaz (2017) iniciam suas fórmulas do EBIT. Hong, Shuting e Meng (2012) e Ataünal e Aybars (2017), por sua vez partem do Lucro Líquido. Por fim, a grande maioria (CHUNG; FIRTH; KIM, 2005; RICHARDSON, 2006; WANG, 2010; ZERNI; KALLUNKI; NILSSON, 2010; MOUSSAVI et al., 2015; NAJMI; SARRAF; DARABI, 2015; CHEN; SUN; XU, 2016; JIANG, 2016) utiliza o FCO [Fluxo de Caixa Operacional] como variável para estimar o FCL.

De acordo com Jensen (1986a, 1986b, 1988), à medida que os FCL se tornavam robustos, a administração tendia a aumentar o consumo e a devorar mais recursos corporativos, causando assim uma perda de valor na empresa. Na Hipótese $1\left(\mathrm{H}_{1}\right)$, espera-se identificar, a partir da análise da dependência entre as variáveis, se o FCL determina o desempenho econômico, medido por IDE das companhias abertas brasileiras.

Considerando o objetivo proposto e tendo como base os principais indicadores reportados nos estudos empíricos internacionais revisados, apresenta-se a construção da $\mathrm{H}_{1}$, desta pesquisa:

$\mathrm{H}_{1}-\mathrm{O}$ Fluxo de Caixa Livre relaciona-se negativamente com os Indicadores de Desempenho Econômico (ROA, Market-to-booke $q$ de Tobin).

A relação negativa sugerida baseia-se no pressuposto de Jensen (1986a, 1986b, 1988) que observou que empresas com grandes $\mathrm{FCL}$, os administradores tendem a investir em projetos ineficientes ou a desperdiçá-lo. Assim, no caso de confirmação da $\mathrm{H}_{1}$, conclui-se que as companhias abertas brasileiras, que possuem grandes montantes de $\mathrm{FCL}$, sofrem com o pressuposto de gastos excessivos pelos administradores de acordo com a Teoria do Free Cash Flow. O teste da $\mathrm{H}_{1}$ será conduzido por meio da análise do coeficiente estimado da variável de interesse (FCL).

Consequentemente, se existem custos de agência em determinada empresa, há perdas residuais e a companhia estaria deixando de aumentar ou melhorar seu desempenho econômico. Então, se há $\mathrm{FCL}$ utilizados de maneira não eficiente, por conseguinte há custos de agência e o desempenho econômico tende a diminuir. Neste sentido, $\mathrm{H}_{1}$ busca a relação direta entre o FCL e os IDE.

Mensurar o que seria o FCL normal ou saudável e o FCL excessivo pode ser um grande desafio. $\mathrm{O}$ que pode ser grande para uma companhia pode não ser para outra, levando em conta particularidades como tamanho, endividamento e setor de cada uma. Para elucidar esta questão, analisou-se a proporção dos FCL por quantis, por meio de regressão quantílica. Esse tipo de estimação permite analisar o comportamento dos coeficientes nas diferentes proporções da variável dependente. Assim, se um FCL excedente realmente for um problema, seu comportamento será perceptível nos maiores quantis, bem como um FCL normal ou médio ficará visível nos quantis médios e um FCL pequeno ou negativo ocorrerá nos menores quantis. Sob esta perspectiva, também é esperado encontrar a relação negativa descrita na $\mathrm{H}_{1}$.

A relação esperada para a estimação com indicadores de desempenho é uma crescente negativa. Os maiores quantis apresentariam uma associação negativa mais forte, momento em que ficaria retratado o $\mathrm{FCL}$ 
excedente, ou seja, o excesso de caixa que é prejudicial para o desempenho econômico. Cabe ressaltar que não foram encontrados estudos semelhantes para esta suposição via regressão quantílica.

\section{PROCEDIMENTOS METODOLÓGICOS}

O caráter quantitativo da pesquisa pode ser observado pela quantificação dos dados advindos da aplicação de instrumentos estatísticos. O caráter descritivo e documental advém da descrição dos resultados de tal aplicação, bem como de utilização de documento para coleta e análise dos dados (demonstrações contábeis).

As informações contábeis foram extraídas do banco de dados Economática em quatro de outubro de 2018. Os dados utilizados são de frequência trimestral, ou seja, nos meses de março, junho, setembro e dezembro, a fim captar efeitos sazonais e aumentar a robustez em relação à utilização de dados anuais. $A$ população utilizada na presente pesquisa foi a totalidade de companhias abertas listadas na [B] ${ }^{3}$ nos anos de 2009 a 2017 (13.176 observações; 366 empresas) [período completo desta pesquisa]. O ano de 2008 apresentou excessivamente ausência de dados (missing data) na Economática', o que afetaria significativamente a análise, optando-se por excluir esse ano.

A amostra final comporta a totalidade das companhias de capital aberto com registro ativo na $[B]^{3}$, incluindo as companhias do setor financeiro, visto que não há motivos para eliminá-las nesse estudo. As exclusões realizadas para se obter a amostra e as subamostras são demonstradas na Figura 1.

Figura 1 - População, amostra e subamostras

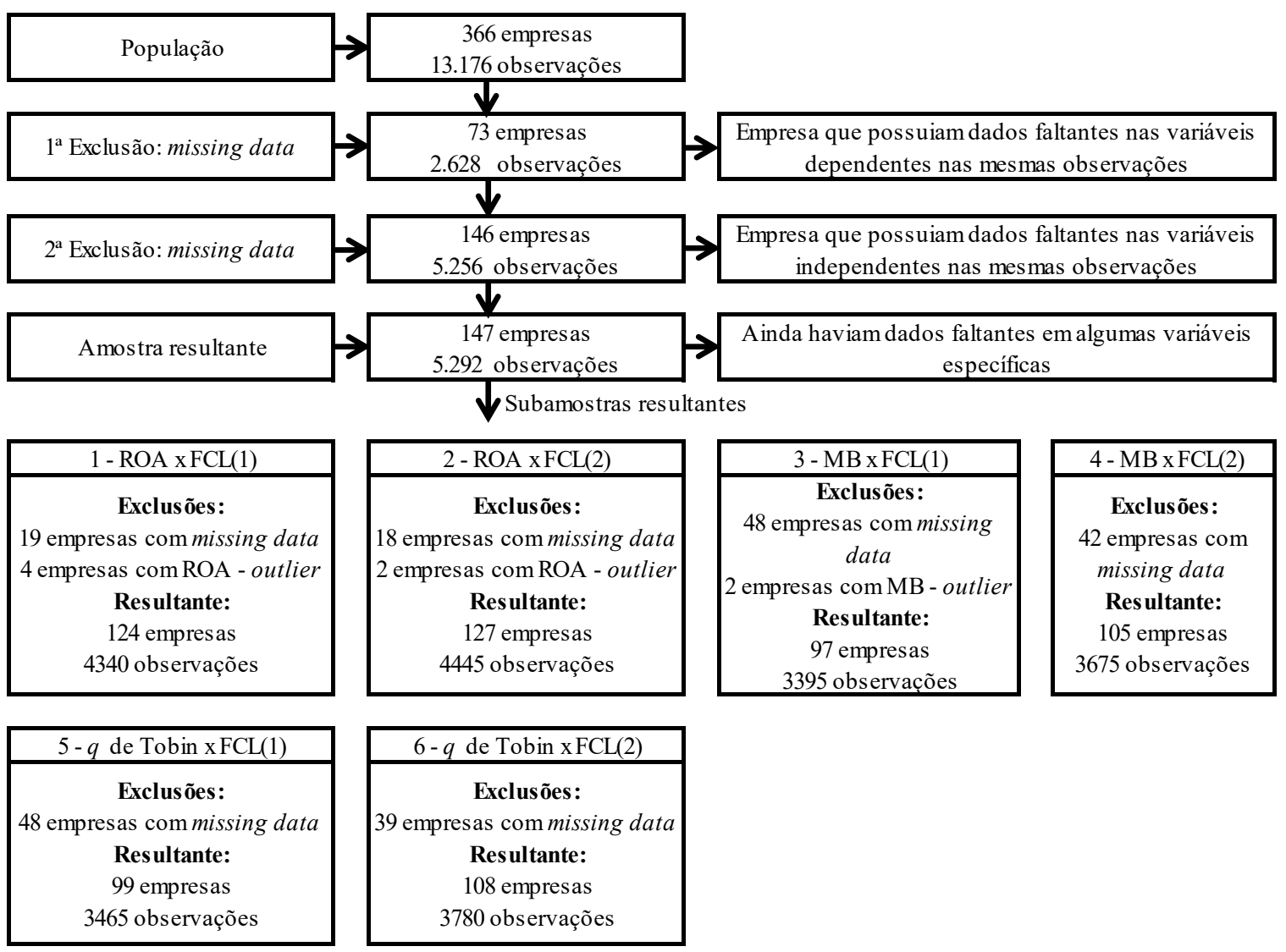

Fonte: Elaborada pelos autores (2018).

A amostra completa resultante tem 5.292 observações empresa-ano e 147 companhias. Destes dados foram realizadas as análises descritivas, porém cabe destacar que ainda havia dados faltantes (missing data) 
específicos para cada variável. Desta forma, com intuito de excluir o mínimo de informações possível, foram realizadas, a partir daí, exclusões dos dados faltantes (missing data) da variável dependente em questão ou do FCL em foco e eventuais outliers para cada modelo econométrico a ser aplicado, resultando em seis subamostras. Para exclusão dos outliers analisou-se a estatística descritiva da amostra.

No caso desta pesquisa, a amostra completa é painel não balanceado tendo em vista que há alguns dados faltantes (missing data) em determinados períodos, em função de carência da própria base da Economática ${ }^{\circ}$ Porém, nas subamostras os painéis são balanceados.

Em um primeiro momento analisou-se as estimações para Mínimos Quadrados Ordinários (MQO) agrupado, Efeitos Fixos (EF) e Efeitos Aleatórios (EA). Em seguida, realizou-se a regressão quantílica, a qual permite analisar a associação entre a variável dependente com as variáveis independentes nos diversos quantis da distribuição condicional. Os estimadores provenientes da regressão quantílica podem ser mais eficientes que os estimadores por meio de $\mathrm{MQO}$ agrupado, em razão dos erros não possuírem uma distribuição normal (KOENKER; BASSETT JUNIOR, 1978). Desta forma, obtém-se um mapeamento mais completo do impacto do $\mathrm{FCL}$ sobre o desempenho econômico, pois é possível investigar como cada quantil responde ao invés de se ter somente uma reta de regressão para o caso da média.

Para selecionar as variáveis dependentes e independentes para a especificação dos modelos econométricos desta pesquisa, levou-se em consideração as variáveis utilizadas nos estudos empíricos internacionais sobre a Teoria do Free Cash Flow. As principais variáveis observadas como relevantes na literatura foram incluídas no modelo econométrico e algumas delas foram adaptadas.

As variáveis independentes consistem em variáveis de interesse e controle. Dentre as variáveis de interesse há duas formas possíveis de mensurar o $\mathrm{FCL}$. Na primeira, denominada $\mathrm{FCL}(1)$ as informações provêm da DFC e na segunda, intitulada FCL(2) os dados são originários da DRE. Utilizam-se variáveis dummy para os seis setores encontrados com maior frequência na amostra. O intuito é captar efeitos por setores econômicos, contudo verificou-se que estudos semelhantes não apresentaram essa relação. Por fim, o Quadro 1 apresenta as variáveis utilizadas na pesquisa.

Quadro 1 - Descrição das variáveis dos modelos econométricos do estudo

\begin{tabular}{|c|c|c|c|}
\hline $\begin{array}{c}\text { Variáveis } \\
\text { Dependentes }\end{array}$ & Descrição da Variável & \begin{tabular}{|c|} 
Relação \\
Esperada
\end{tabular} & Referências \\
\hline $\begin{array}{l}\text { Return on Assets } \\
\text { (ROA) }\end{array}$ & Lucro Líquido/Ativo Total & & $\begin{array}{l}\text { Chung , Firth e Kim (2005), Wang } \\
\text { (2010) e Hau (2017) }\end{array}$ \\
\hline Market-to-Book(MB) & $\begin{array}{l}\text { Valor de Mercado da } \\
\text { Empresa/Patrimônio Líquido }\end{array}$ & & $\begin{array}{l}\text { Chung, Firth e Kim (2005), Almeida, } \\
\text { Sousa e Rodrigues (2009) e Bastos, } \\
\text { Nakamura e Basso (2009) }\end{array}$ \\
\hline$q$ de Tobin & $\begin{array}{l}\text { (Valor de Mercado da } \\
\text { Empresa+Passivo } \\
\text { Circulante+Passivo Não Circulante- } \\
\text { Ativo Circulante)/Ativo Total }\end{array}$ & & $\begin{array}{l}\text { Chung, Firth e Kim (2005), Wang } \\
\text { (2010), Mansourlakoraj e Sepasi } \\
\text { (2015), Najmi, Sarraf e Darabi (2015) } \\
\text { e Kadioglu, Kilic e Yilmaz (2017) }\end{array}$ \\
\hline \multicolumn{4}{|l|}{$\begin{array}{l}\text { Variáveis } \\
\text { Independentes }\end{array}$} \\
\hline \multicolumn{4}{|l|}{$\begin{array}{l}\text { Variáveis de } \\
\text { Interesse }\end{array}$} \\
\hline $\begin{array}{l}\text { Fluxo de Caixa Livre } \\
-\mathrm{FCL}(1)\end{array}$ & $\begin{array}{l}\text { (Fluxo de Caixa Operacional- } \\
\text { CAPEX-Dividendos)/Ativo Total }\end{array}$ & - & Zerni, Kallunki e Nilsson (2010) \\
\hline $\begin{array}{l}\text { Fluxo de Caixa Livre } \\
- \text { FCL (1) - t1 }\end{array}$ & $\begin{array}{l}\text { Defasado um trimestre(Fluxo de } \\
\text { Caixa Operacional-CAPEX- } \\
\text { Dividendos)/Ativo Total }\end{array}$ & - & Zerni, Kallunki e Nilsson (2010) \\
\hline $\begin{array}{l}\text { Fluxo de Caixa Livre } \\
\text { - FCL (2) }\end{array}$ & $\begin{array}{l}\text { (EBITDA-Imposto de Renda e } \\
\text { Contribuição Social-Despesa } \\
\text { Financeira-Dividendos)/Receita } \\
\text { Operacional Líquida }\end{array}$ & - & Wang (2010) \\
\hline
\end{tabular}




\begin{tabular}{|l|l|l|l|}
\hline $\begin{array}{l}\text { Fluxo de Caixa Livre } \\
- \text { FCL (2)- t1 }\end{array}$ & $\begin{array}{l}\text { Defasado um trimestre(EBITDA- } \\
\text { Imposto de Renda e Contribuição } \\
\text { Social-Despesa Financeira- } \\
\text { Dividendos)/Receita Operacional } \\
\text { Líquida }\end{array}$ & - & Wang (2010) \\
\hline $\begin{array}{l}\text { Variáveis de } \\
\text { Controle }\end{array}$ & $\begin{array}{l}\text { Logaritmo do Ativo Total } \\
\text { Tamanho (TAM) }\end{array}$ & & Kadioglu, Kilic e Yilmaz (2017) \\
\hline $\begin{array}{l}\text { Endividamento } \\
\text { (END) }\end{array}$ & $\begin{array}{l}\text { (Passivo Circulante+Passivo Não } \\
\text { Circulante)/Ativo Total }\end{array}$ & $\begin{array}{l}\text { Bastos, Nakamura e Basso (2009) e } \\
\text { Kadioglu, Kilic e Yilmaz (2017) }\end{array}$ \\
\hline Segmento (SEG) & $\begin{array}{l}\text { Setor Econômico Bovespa } \\
\text { (Economática })\end{array}$ & \\
\hline
\end{tabular}

Fonte: Elaborado pelos autores (2018).

A presente pesquisa se propôs a analisar os resultados dos modelos econométricos aplicados a cada variável, com o objetivo de identificar diferenças entre as medidas de FCL. O modelo econométrico foi formulado baseando-se nos estudos de Wang (2010), Mansourlakoraj e Sepasi (2015) e Moussavi et al. (2015). Assim, a Equação (1) expõe o modelo que visa responder à questão problema:

$\mathrm{IDE}_{\mathrm{i}, \mathrm{t}}=a+\beta_{1} \mathrm{FCL}_{\mathrm{i}, \mathrm{t}}+\beta_{2} \mathrm{FCL}_{\mathrm{i}, \mathrm{t}-1}+\beta_{3} \mathrm{TAM}_{\mathrm{i}, \mathrm{t}}+\beta_{4} \mathrm{END}_{\mathrm{i}, \mathrm{t}}+\beta_{5}$ DumSET $_{\mathrm{i}}+\varepsilon_{\mathrm{i}}$

Em que:

$I E_{i, t}=$ Indicador de Desempenho Econômico da empresa i no tempo t.

$a=$ Intercepto da reta.

$\beta_{1}$ a $\beta_{5}=$ Coeficientes angulares.

$\mathrm{FCL}_{\mathrm{i}, \mathrm{t}}=$ Fluxo de Caixa Livre da empresa i no tempo $t$.

$\mathrm{FCL}_{\mathrm{i}, \mathrm{t}-1}=$ Fluxo de Caixa Livre da empresa i no tempo $\mathrm{t}-1$.

$\mathrm{TAM}_{\mathrm{i}, \mathrm{t}}=$ Indica o Tamanho da empresa i no tempo $\mathrm{t}$.

$E N D_{i, t}=$ Indica Endividamento da empresa i no tempo $t$.

DumSET $_{\mathrm{i}}=$ Indica o Setor Econômico da empresa i, representado por variáveis dummy.

$\varepsilon_{\mathrm{i}}=$ Termo de erro.

A Tabela 1 apresenta a relação esperada entre as variáveis de forma resumida.

Tabela 1 - Resumo da relação esperada entre as variáveis

\begin{tabular}{cc}
\hline Variável Dependente & Fluxo de Caixa Livre (FCL) \\
\hline ROA & - \\
MB & - \\
qde Tobin & - \\
\hline \multicolumn{2}{c}{ Fonte: Elaborado pelo autor (2018) }
\end{tabular}

Espera-se que os resultados sejam uma associação negativa entre os altos FCL e os IDE, de acordo com a Teoria do Free Cash Flow proposta por Jensen (1986a, 1986b, 1988). Caso positivo, haverá indicativo de problemas agência nas empresas da $[B]^{3}$.

\section{APRESENTAÇÃO E ANÁLISE DOS RESULTADOS}

Essa seção apresenta a estatística descritiva das variáveis, posteriormente, a matriz de correlação, os principais resultados encontrados nas regressões e as análises feitas a partir desses resultados. 


\subsection{Estatística descritiva das variáveis}

Nas Tabelas 2 e 3 apresentam-se as estatísticas descritivas das variáveis quantitativas desta pesquisa, antes e depois do tratamento dos outliers, respectivamente.

Tabela 2 - Estatística descritiva das variáveis - amostra completa - antes do tratamento dos dados faltantes e outliers

\begin{tabular}{ccccccc}
\hline & Média & Mediana & Mínimo & Máximo & Desvio-Padrão & Observações \\
\hline ROA & $-0,0198$ & 0,0082 & $-66,2759$ & 3,5997 & 1,0258 & 5292 \\
MB & 1,9735 & 1,2254 & $-41,4479$ & 103,4623 & 4,7270 & 4904 \\
q de Tobin & 1,0837 & 0,7997 & $-0,3024$ & 47,2157 & 1,6644 & 4904 \\
FCL(1) & $-0,0302$ & $-0,0008$ & $-120,0990$ & 0,7665 & 1,6702 & 5223 \\
FCL(2) & 1,5123 & 0,0231 & $-1439,1176$ & 785,1000 & 34,9487 & 5125 \\
TAM & 15,0045 & 15,0936 & $-1,0385$ & 20,6524 & 2,0284 & 5292 \\
END & 0,8079 & 0,5815 & 0,0003 & 387,7062 & 5,9818 & 5292 \\
\hline
\end{tabular}

Fonte: Elaborada a partir dos dados da pesquisa (2018).

Tabela 3 - Estatística descritiva das principais variáveis - subamostras completas - depois do tratamento dos dados faltantes e outliers

\begin{tabular}{|c|c|c|c|c|c|c|c|}
\hline & Subamostra & Média & Mediana & Mínimo & Máximo & Desvio-Padrão & Observações \\
\hline $\mathrm{ROA}$ & \multirow{2}{*}{5} & 0,0067 & 0,0085 & $-0,9037$ & 0,7540 & 0,0399 & 4464 \\
\hline $\mathrm{FCL}(1)$ & & $-0,0028$ & $-0,0010$ & $-0,4186$ & 0,5079 & 0,0392 & 4464 \\
\hline ROA & \multirow{2}{*}{6} & 0,0066 & 0,0086 & $-0,9037$ & 0,7540 & 0,0415 & 4572 \\
\hline $\mathrm{FCL}(2)$ & & $-0,0758$ & 0,0230 & $-43,8358$ & 72,5899 & 2,3683 & 4572 \\
\hline MB & \multirow{2}{*}{7} & 2,1589 & 1,2907 & $-15,2328$ & 98,6277 & 4,1363 & 3492 \\
\hline $\mathrm{FCL}(1)$ & & $-0,0032$ & $-0,0010$ & $-0,4186$ & 0,3284 & 0,0378 & 3492 \\
\hline MB & \multirow{2}{*}{8} & 2,0782 & 1,2626 & $-14,9681$ & 98,6277 & 3,9587 & 3780 \\
\hline $\mathrm{FCL}(2)$ & & 2,4314 & 0,0269 & $-146,0300$ & 785,1000 & 32,7089 & 3780 \\
\hline q de Tobin & \multirow{2}{*}{9} & 0,9759 & 0,8040 & $-0,3024$ & 6,8401 & 0,8090 & 3564 \\
\hline $\mathrm{FCL}(1)$ & & $-0,0030$ & $-0,0010$ & $-0,4186$ & 0,3284 & 0,0380 & 3564 \\
\hline \multirow{2}{*}{$\begin{array}{l}\text { q de Tobin } \\
\text { FCL(2) }\end{array}$} & \multirow{2}{*}{10} & 0,9818 & 0,7948 & $-0,3024$ & 6,8401 & 0,8499 & 3888 \\
\hline & & 2,3604 & 0,0260 & $-146,0300$ & 785,1000 & 32,2542 & 3888 \\
\hline
\end{tabular}

Fonte: Elaborada a partir dos dados da pesquisa (2018).

Observa-se que, na Tabela 2, o FCL(1) e FCL(2) apresentam estatísticas consideravelmente diferentes entre si, o que corrobora o fato dessa medida ser arbitrária e ao mesmo tempo subjetiva. A companhia que apresentou o maior $\mathrm{FCL}(1)$ e $\mathrm{FCL}(2)$ foi a Itausa (Financeiro e outros) e a entidade que apresentou o menor FCL(1) e FCL(2) foi Petrobras (Petróleo, gás e biocombustíveis).

Analisando as Tabelas 2 e 3, verifica-se que após o tratamento dos dados faltantes (missing data) e alguns outliers, todas as subamostras tiveram seus desvios-padrão reduzidos. O Return on Assets (ROA) foi a variável que apresentou os outliers mais extremos, tanto para o máximo quanto para o mínimo.

\subsection{Matriz de correlação das variáveis}

A Tabela 4 apresenta a correlação entre as variáveis do modelo econométrico, antes do tratamento dos outliers.

Tabela 4 - Matriz de correlação das variáveis - amostra completa - antes do tratamento dos dados faltantes e outliers 


\begin{tabular}{cccccccc}
\hline & ROA & Market-to-Book & q de Tobin & FCL(1) & FCL(2) & TAM & END \\
\hline ROA & 1 & & & & & & \\
Market-to-Book & 0,0547 & 1 & & & & & \\
q de Tobin & 0,1041 & 0,1118 & 1 & & & & \\
FCL(1) & 0,8892 & $-0,0052$ & $-0,1514$ & 1 & & & \\
FCL(2) & 0,0757 & $-0,0131$ & $-0,0324$ & 0,0023 & 1 & & \\
TAM & 0,1828 & 0,0350 & $-0,3043$ & 0,1199 & $-0,0576$ & 1 & \\
END & $-0,7789$ & $-0,0637$ & 0,6523 & $-0,4401$ & $-0,0965$ & $-0,1981$ & 1 \\
\hline
\end{tabular}

Fonte: Elaborada a partir dos dados da pesquisa (2018).

Como se pode observar entre as variáveis independentes a maior correlação foi de $-0,4401$, ficando dentro do nível de correlação aceito. Para Hair et al. (2009), valores elevados, maiores ou iguais a 0,90 de correlação, indicam presença de multicolinearidade. Assim, verificou-se que não há multicolinearidade entre as variáveis do estudo.

\subsection{Resultados das regressões pelo modelo de mínimos quadrados ordinários}

O teste de White foi realizado nas seis subamostras a fim de detectar presença de heterocedasticidade. Dado que todos apresentaram resultado positivo, os modelos foram estimados utilizando erros padrão robustos (ou HAC, do inglês Heteroskedasticity and autocorrelation consistent) para correção do problema. Para testar a multicolinearidade utilizou-se o Fator de Inflação de Variância (FIV, do inglês Variance Inflation Fator). Tendo em vista que o teste apresentou valores próximos a um para todas as variáveis em todas as subamostras, pode-se concluir pela inexistência de multicolinearidade.

A análise nesse estudo concentra-se nas variáveis de interesse $[F C L(1)$ e $F C L(2)]$, explicando o relacionamento dos componentes do $\mathrm{FCL}$ com a variável dependente, que é medida pelos betas (coeficientes) da regressão. Apresentam-se, na Tabela 5, os resultados dos modelos de MQO, EF e EA para os IDE com o FCL(1) e FCL(2). 
Tabela 5 - Estimação da relação entre os Indicadores de Desempenho Econômico (IDE) com o Fluxo de Caixa Livre (1) e (2) de 2009 a 2017

\begin{tabular}{|c|c|c|c|c|c|c|c|c|c|}
\hline & \multicolumn{3}{|c|}{ ROA } & \multicolumn{3}{|c|}{ MB } & \multicolumn{3}{|c|}{$q$ de Tobin } \\
\hline & MQO & EF & EA & MQO & EF & EA & MQO & EF & EA \\
\hline \multirow[t]{2}{*}{ Constante } & $-0,001843$ & 0,084320 & 0,013087 & $-0,237563$ & 15,878780 & 10,798960 & 0,348810 & 5,781718 & 5,329007 \\
\hline & $(-0,1553)$ & $(2,3155)^{* *}$ & $(0,9913)$ & $(-0,0690)$ & $(2,6407)^{* * *}$ & $(2,5884)^{* * *}$ & $(0,3935)$ & $(4,1801)^{* * *}$ & $(3,9391)^{* * *}$ \\
\hline \multirow[t]{2}{*}{$\mathrm{FCL}(1)$} & 0,051988 & 0,056160 & 0,051825 & $-2,461400$ & 0,317363 & 0,025319 & $-0,565398$ & $-0,585061$ & $-0,607213$ \\
\hline & $(2,1089)^{* *}$ & $(2,1967)^{* *}$ & $(2,078)^{* *}$ & $(-1,749)^{*}$ & $(0,2069)$ & $(0,0171)$ & $(-1,1595)$ & $(-2,0751)^{* *}$ & $(-2,1430)^{* *}$ \\
\hline \multirow[t]{2}{*}{$\mathrm{FCL}(1)(-1)$} & 0,009869 & 0,009174 & 0,007130 & $-0,745139$ & 1,553196 & 1,367554 & $-0,083966$ & $-0,315193$ & $-0,323629$ \\
\hline & $(0,4070)$ & $(0,3999)$ & $(0,3080)$ & $(-0,4135)$ & $(0,7583)$ & $(0,6790)$ & $(-0,1720)$ & $(-1,1891)$ & $(-1,2332)$ \\
\hline \multirow[t]{2}{*}{ TAM } & 0,001805 & $-0,002660$ & 0,001142 & 0,125346 & $-0,893335$ & $-0,565577$ & 0,029668 & $-0,327028$ & $-0,285956$ \\
\hline & $(2,7921)^{* * *}$ & $(-1,0944)$ & $(1,4706)$ & $(0,5928)$ & $(-2,1776)^{* *}$ & $(-1,9844)^{* *}$ & $(0,6559)$ & $(-3,7789)^{* * *}$ & $(-3,6832)^{* * *}$ \\
\hline \multirow[t]{2}{*}{ END } & $-0,039552$ & $-0,060624$ & $-0,047352$ & 0,513136 & 0,188834 & 0,317920 & 0,399337 & 0,395280 & 0,406200 \\
\hline & $(-6,4417)^{* * *}$ & $(-4,3762)^{* * *}$ & $(-5,5499)^{* * *}$ & $(0,6367)$ & $(0,1712)$ & $(0,3145)$ & $(2,2356)^{* * *}$ & $(4,2591)^{* * *}$ & $(4,3751)^{* * *}$ \\
\hline \multirow[t]{2}{*}{ Bens Industriais } & 0,007003 & & 0,007221 & 0,060559 & & $-0,618579$ & $-0,154192$ & & $-0,515860$ \\
\hline & $(1,3548)$ & & $(1,395)$ & $(0,0833)$ & & $(-0,7269)$ & $(-0,4744)$ & & $(-1,2823)$ \\
\hline \multirow[t]{2}{*}{ Consumo cíclico } & 0,007193 & & 0,006834 & 0,569716 & & $-0,229917$ & $-0,048523$ & & $-0,422233$ \\
\hline & $(1,3387)$ & & $(1,2830)$ & $(0,5973)$ & & $(-0,2520)$ & $(-0,1427)$ & & $(-1,0316)$ \\
\hline \multirow{2}{*}{$\begin{array}{l}\text { Consumo não } \\
\text { cíclico }\end{array}$} & 0,009741 & & 0,009600 & 1,924165 & & 2,027820 & 0,578568 & & 0,542591 \\
\hline & $(1,4182)$ & & $(1,3650)$ & $(1,1724)$ & & $(1,1903)$ & $(1,1852)$ & & $(0,9307)$ \\
\hline \multirow{2}{*}{$\begin{array}{l}\text { Financeiro e } \\
\text { outros }\end{array}$} & 0,001159 & & $-0,000499$ & 0,987527 & & 0,966424 & $-0,061906$ & & $-0,066190$ \\
\hline & $(0,2178)$ & & $(-0,0924)$ & $(0,5819)$ & & $(0,6055)$ & $(-0,1813)$ & & $(-0,1636)$ \\
\hline \multirow[t]{2}{*}{ Materiais básicos } & $-0,000109$ & & $-0,000231$ & $-0,962443$ & & $-0,697428$ & $-0,365214$ & & $-0,257997$ \\
\hline & $(-0,0219)$ & & $(-0,0455)$ & $(-1,6646)^{*}$ & & $(-0,9654)$ & $(-1,2922)$ & & $(-0,6560)$ \\
\hline \multirow[t]{2}{*}{ Utilidade pública } & 0,006759 & & 0,007279 & $-0,797054$ & & $-0,289800$ & $-0,201620$ & & 0,020865 \\
\hline & $(1,4121)$ & & $(1,5473)$ & $(-1,3272)$ & & $(-0,4397)$ & $(-0,7124)$ & & $(0,0577)$ \\
\hline \multirow{2}{*}{$\begin{array}{c}\mathrm{R}^{2} \text { ajustado } \\
\text { Intervalos no } \\
\text { tempo }\end{array}$} & 0,0874 & 0,1638 & 0,0495 & 0,0413 & 0,4590 & 0,0092 & 0,1045 & 0,7770 & 0,1394 \\
\hline & \multicolumn{3}{|l|}{35} & \multicolumn{3}{|l|}{35} & \multicolumn{3}{|l|}{35} \\
\hline Empresas & \multicolumn{3}{|l|}{124} & \multicolumn{3}{|l|}{97} & \multicolumn{3}{|l|}{99} \\
\hline Observações & \multicolumn{3}{|l|}{4340} & \multicolumn{3}{|l|}{3395} & \multicolumn{3}{|l|}{3465} \\
\hline Teste $\mathrm{F}$ & \multirow{3}{*}{\multicolumn{3}{|c|}{$\begin{array}{l}F(123,4212)=4,44 \text { com } p \text {-valor } 0,0000 \\
L M=19439,59 \text { com } p \text {-valor } 0,0000 \\
H=29,48 \text { com } p \text {-valor } 0,0000\end{array}$}} & \multirow{3}{*}{\multicolumn{3}{|c|}{$\begin{array}{l}F(96,3294)=30,98 \text { com } p \text {-valor } 0,0000 \\
L M=36760,70 \text { com } p \text {-valor } 0,0000 \\
H=23,09 \text { com } p \text {-valor } 0,0001\end{array}$}} & $F(98,3362)=1$ & 9 com p-valor & 000 \\
\hline \multirow{4}{*}{$\begin{array}{l}\text { Breusch-Pagan } \\
\text { Hausman }\end{array}$} & & & & & & & $\mathrm{LM}=36726,7$ & n p-valor 0,00 & \\
\hline & & & & & & & $\mathrm{H}=53,17 \mathrm{com}$ & alor 0,0000 & \\
\hline & & ROA & & & MB & & & $q$ de Tobin & \\
\hline & MQO & EF & EA & MQO & EF & EA & MQO & EF & EA \\
\hline
\end{tabular}




\begin{tabular}{|c|c|c|c|c|c|c|c|c|c|}
\hline Constante & $\begin{array}{c}0,013150 \\
(0,9972)\end{array}$ & $\begin{array}{c}0,090358 \\
(2,4020)^{* * *}\end{array}$ & $\begin{array}{l}0,026344 \\
(1,8978)^{*}\end{array}$ & $\begin{array}{c}2,701807 \\
(0,8365)\end{array}$ & $\begin{array}{c}17,134530 \\
(2,7430)^{* * * *}\end{array}$ & $\begin{array}{l}12,736300 \\
(2,9827)^{* * *}\end{array}$ & $\begin{array}{c}1,680244 \\
(1,4204)\end{array}$ & $\begin{array}{c}4,999602 \\
(3,7639)^{* * * *}\end{array}$ & $\begin{array}{c}5,063512 \\
(3,9609)^{* * * *}\end{array}$ \\
\hline \multirow[t]{2}{*}{$\mathrm{FCL}(2)$} & 0,002905 & 0,002721 & 0,002750 & $-0,003351$ & 0,000475 & 0,000021 & $-0,000783$ & 0,000184 & 0,000155 \\
\hline & $(1,9036)^{*}$ & $(1,9917)^{* *}$ & $(1,9577)^{* *}$ & $(-1,4852)$ & $(0,8875)$ & $(0,0543)$ & $(-2,6390)^{* * *}$ & $(7,2562)^{* * *}$ & $(5,8274)^{* * *}$ \\
\hline \multirow[t]{2}{*}{$\mathrm{FCL}(2)(-1)$} & $-0,000215$ & $-0,000384$ & $-0,000342$ & $-0,003540$ & 0,000366 & $-0,000075$ & $-0,000859$ & 0,000128 & 0,000100 \\
\hline & $(-0,2845)$ & $(-0,4318)$ & $(-0,4026)$ & $(-1,5410)$ & $(0,7449)$ & $(-0,2142)$ & $(-2,7587)^{* * *}$ & $(4,0308)^{* * *}$ & $(2,8954)^{* * *}$ \\
\hline \multirow[t]{2}{*}{ TAM } & 0,001178 & $-0,003334$ & 0,000503 & $-0,021823$ & $-1,044376$ & $-0,702762$ & $-0,022651$ & $-0,284866$ & $-0,253465$ \\
\hline & $(1,6284)^{*}$ & $(-1,3585)$ & $(0,6062)$ & $(-0,1139)$ & $(-2,2247)^{* *}$ & $(-2,1578)^{* *}$ & $(-0,4246)$ & $(-3,3851)^{* * * *}$ & $(-3,3798)^{* * *}$ \\
\hline \multirow[t]{2}{*}{ END } & $-0,040268$ & $-0,054642$ & $-0,045440$ & 0,339487 & 1,571542 & 1,374852 & 0,134013 & 0,537986 & 0,516608 \\
\hline & $(-5,8410)^{* * *}$ & $(-4,0759)^{* * *}$ & $(-5,3392)^{* * * *}$ & $(0,3470)$ & $(0,7089)$ & $(0,6977)$ & $(0,6156)$ & $(4,4469)^{* * * *}$ & $(4,3398)^{* * *}$ \\
\hline \multirow[t]{2}{*}{ Bens Industriais } & 0,000562 & & 0,000464 & $-1,058857$ & & $-1,774093$ & $-0,581299$ & & $-0,866326$ \\
\hline & $(0,1103)$ & & $(0,0933)$ & $(-1,3962)$ & & $(-1,9402)^{*}$ & $(-1,2931)$ & & $(-1,9410)^{*}$ \\
\hline \multirow[t]{2}{*}{ Consumo cíclico } & 0,000086 & & 0,000015 & $-0,335511$ & & $-0,977821$ & $-0,530161$ & & $-0,749444$ \\
\hline & $(0,0168)$ & & $(0,0029)$ & $(-0,3582)$ & & $(-1,0188)$ & $(-1,1623)$ & & $(-1,6540)^{*}$ \\
\hline \multirow{2}{*}{$\begin{array}{l}\text { Consumo não } \\
\text { cíclico }\end{array}$} & 0,003961 & & 0,004334 & 1,120007 & & 1,522943 & 0,152911 & & 0,084712 \\
\hline & $(0,5959)$ & & $(0,6430)$ & $(0,7134)$ & & $(0,9368)$ & $(0,2888)$ & & $(0,1453)$ \\
\hline \multirow{2}{*}{$\begin{array}{c}\text { Financeiro e } \\
\text { outros }\end{array}$} & $-0,005893$ & & $-0,006276$ & 0,696113 & & 0,145904 & $-0,279828$ & & $-0,446060$ \\
\hline & $(-1,0569)$ & & $(-1,1444)$ & $(0,3930)$ & & $(0,0913)$ & $(-0,6115)$ & & $(-0,9574)$ \\
\hline \multirow[t]{2}{*}{ Materiais básicos } & $-0,005938$ & & $-0,005877$ & $-1,393977$ & & $-1,252337$ & $-0,770134$ & & $-0,723273$ \\
\hline & $(-1,2034)$ & & $(-1,1922)$ & $(-2,0698)^{* *}$ & & $(-1,4879)$ & $(-1,8924)^{*}$ & & $(-1,5762)$ \\
\hline \multirow[t]{2}{*}{ Utilidade pública } & 0,004112 & & 0,004887 & $-1,011047$ & & $-0,601396$ & $-0,453140$ & & $-0,316219$ \\
\hline & $(0,8716)$ & & $(1,0376)$ & $(-1,4595)$ & & $(-0,7663)$ & $(-1,1414)$ & & $(-0,7179)$ \\
\hline \multirow{2}{*}{$\begin{array}{c}\mathrm{R}^{2} \text { ajustado } \\
\text { Intervalos no } \\
\text { tempo }\end{array}$} & 0,1119 & 0,1800 & 0,0720 & 0,0376 & 0,4633 & 0,0158 & 0,1065 & 0,7978 & 0,0898 \\
\hline & \multicolumn{3}{|l|}{35} & \multicolumn{3}{|l|}{35} & 35 & & \\
\hline Empresas & \multicolumn{3}{|l|}{127} & \multicolumn{3}{|l|}{105} & \multicolumn{3}{|l|}{108} \\
\hline Observações & \multicolumn{3}{|l|}{4445} & \multicolumn{3}{|l|}{3675} & \multicolumn{3}{|l|}{3780} \\
\hline Teste F & \multicolumn{3}{|c|}{$F(126,4314)=4,14$ com $p$-valor 0,0000} & \multicolumn{3}{|c|}{$F(104,3566)=31,45$ com p-valor 0,0000} & \multicolumn{3}{|c|}{$F(107,3668)=139,16$ com p-valor 0,0000} \\
\hline Breusch-Pagan & \multicolumn{3}{|c|}{$L M=21150,17$ com $p$-valor 0,0000} & \multicolumn{3}{|c|}{$\mathrm{LM}=45531,29$ com p-valor 0,0000} & \multicolumn{3}{|c|}{$\mathrm{LM}=41994,17$ com $\mathrm{p}$-valor 0,0000} \\
\hline Hausman & \multicolumn{3}{|c|}{$\mathrm{H}=24,17$ com $\mathrm{p}$-valor 0,0001} & \multicolumn{3}{|c|}{$\mathrm{H}=27,46$ com $\mathrm{p}$-valor 0,0001} & \multicolumn{3}{|c|}{$\mathrm{H}=34,16$ com $\mathrm{p}$-valor 0,0000} \\
\hline
\end{tabular}

Nota: Estimação com HAC. ${ }^{* * *},{ }^{* *} \mathrm{e}^{*}$ representam valores significativos a $1 \%, 5 \%$ e $10 \%$ respectivamente.

Fonte: Elaborada a partir dos dados da pesquisa (2018). 
De acordo com a Tabela 5 o coeficiente do $\mathrm{FCL}(1)$ e do $\mathrm{FCL}(1)(-1)$ é positivo nos três modelos para a estimação ROA e FCL(1), o que indica que essa variável relaciona-se positivamente com o ROA das empresas da $[B]^{3}$, contrário a relação esperada (Tabela 1). O FCL(1) apresentou significância estatística de $5 \%$ nos três modelos estimados, o que torna os resultados mais robustos. Uniformemente, os resultados de Chung, Firth e Kim (2005), que analisaram companhias de todo o mundo, indicaram que a relação entre o FCL e o ROA é positiva e significativa. Wang (2010), em seu estudo, observou uma relação positiva e significativa entre o FCL defasado e o ROA nas empresas abertas chinesas, e Hau (2017) constatou o mesmo em companhias vietnamitas, entretanto, nos modelos estimados entre ROA e FCL(1)(-1), essa variável não é estatisticamente significativa. Os modelos para ROA e FCL(1) evidenciaram relação negativa e significância estatística de $1 \%$ entre ROA e endividamento.

Na estimação ROA e $\mathrm{FCL}(2)$, a variável $\mathrm{FCL}(2)$ apresentou coeficiente positivo e significativo nos três modelos de painel, corroborando a estimação ROA e FCL(1) e o estudo de Chung, Firth e Kim (2005). A significância estatística ficou em 10\% para o MQO agrupado e em 5\% para efeitos fixos e aleatórios, tornando forte o poder de explicação dessa variável sobre o ROA. Observa-se, ainda, que ROA e FCL(2)(-1) formaram uma ligação negativa e sem significância.

O coeficiente do FCL(1), na estimação com o Market-to-Book (MB), não apresentou consistência de sinal nos modelos, sendo negativo no MQO agrupado e positivo em efeitos fixos e efeitos aleatórios. O FCL(1) revelou significância estatística de 10\% apenas para o MQO agrupado, os outros modelos não apresentaram resultado significante. Em comparação a este estudo, Moussavi et al. (2015) testaram o poder de explicação do FCL sobre o MB em empresas abertas iranianas, porém encontraram um coeficiente muito baixo, positivo e sem significância estatística. Na estimação entre $\mathrm{MB}$ e $\mathrm{FCL}(2)$, as evidências não indicaram significância nem regularidade de sinal do coeficiente das variáveis de interesse $[F C L(2)$ e $F C L(2)(-1)]$.

Pelos resultados da estimação, a relação entre $\mathrm{FCL}(1)$ e $\mathrm{FCL}(1)(-1)$ com $q$ de Tobin é negativa, porém estatisticamente significativo somente nos modelos de efeitos fixos e aleatórios do FCL(1). Os coeficientes do $\mathrm{FCL}(2)$ e $\mathrm{FCL}(2)(-1)$ mostraram relação negativa e significativa a $1 \%$ com o $q$ de Tobin no MQO agrupado, contudo nos efeitos fixos e efeitos aleatórios a associação foi positiva e significativa a $1 \%$, ficando evidente a forte conexão entre as variáveis de interesse e a variável dependente.

\subsection{Resultados das regressões quantílicas}

A análise nesta seção concentra-se na significância estatística das variáveis de interesse $[\mathrm{FCL}(1)$ e FCL(2)] nos quantis mais extremos. Conforme a Teoria do Free Cash Flow de Jensen (1986a, 1986b, 1988), quanto maior o FCL, maior seria os custos de agência. Assim, espera-se uma associação negativa e significativa entre os grandes FCL e IDE, visto que FCL em excesso estaria associado ao desperdício de recursos.

Para testar se a regressão quantílica é eficaz, realiza-se o teste de Wald. Para p-valores menores que 0,05 conclui-se que os coeficientes diferem entre os valores dos quantis e que os quantis condicionais estabelecidos não são idênticos. Todas as regressões apresentaram p-valores de 0,0000 para o teste de Wald, confirmando que os quantis são diferentes e é relevante utilizar esse tipo de estimação.

Na Tabela 6 apresentam-se os resultados da regressão quantílica para o ROA com o FCL(1) e FCL(2). 
Tabela 6 - Estimação da relação entre o Return on Assets (ROA) com o Fluxo de Caixa Livre (1) e (2) nos diferentes quantis de 2009 a 2017

\begin{tabular}{|c|c|c|c|c|c|c|c|}
\hline \multirow[b]{2}{*}{ Quantis } & \multicolumn{7}{|c|}{ ROA } \\
\hline & 0.125 & 0.250 & 0.375 & 0.500 & 0.625 & 0.750 & 0.875 \\
\hline Constante & $\begin{array}{c}-0,036760 \\
(-5,1995)^{* * *}\end{array}$ & $\begin{array}{c}-0,014034 \\
(-3,4952)^{* * *}\end{array}$ & $\begin{array}{l}0,000303 \\
(0,09257)\end{array}$ & $\begin{array}{l}0,005201 \\
(1,8657)^{*}\end{array}$ & $\begin{array}{c}0,017618 \\
(5,31891)^{* * *}\end{array}$ & $\begin{array}{c}0,030265 \\
(7,82742)^{* * * *}\end{array}$ & $\begin{array}{c}0,057486 \\
(7,51774)^{* * * *}\end{array}$ \\
\hline $\mathrm{FCL}(1)$ & $\begin{array}{l}0,011788 \\
(0,91319)\end{array}$ & $\begin{array}{c}0,016984 \\
(1,82156)^{*}\end{array}$ & $\begin{array}{c}0,023671 \\
(2,84895)^{* * *}\end{array}$ & $\begin{array}{c}0,018959 \\
(2,01678)^{* *}\end{array}$ & $\begin{array}{c}0,018880 \\
(2,01821)^{* *}\end{array}$ & $\begin{array}{c}0,034478 \\
(3,41557)^{* * * *}\end{array}$ & $\begin{array}{c}0,035325 \\
(2,44824)^{* *}\end{array}$ \\
\hline $\mathrm{FCL}(1)(-1)$ & $\begin{array}{l}0,013870 \\
(0,98632)\end{array}$ & $\begin{array}{c}-0,013069 \\
(-1,5747)\end{array}$ & $\begin{array}{l}0,002529 \\
(0,29515)\end{array}$ & $\begin{array}{l}0,002219 \\
(0,29709)\end{array}$ & $\begin{array}{l}0,000808 \\
(0,09194)\end{array}$ & $\begin{array}{l}0,005812 \\
(0,60939)\end{array}$ & $\begin{array}{l}0,014086 \\
(1,15217)\end{array}$ \\
\hline TAM & $\begin{array}{c}0,003633 \\
(9,78086)^{* * * *}\end{array}$ & $\begin{array}{c}0,002257 \\
(10,4483)^{* * *}\end{array}$ & $\begin{array}{c}0,001510 \\
(8,14010)^{* * * *}\end{array}$ & $\begin{array}{c}0,001362 \\
(7,29050)^{* * * *}\end{array}$ & $\begin{array}{c}0,000788 \\
(3,80632)^{* * * *}\end{array}$ & $\begin{array}{l}0,000205 \\
(0,77146)\end{array}$ & $\begin{array}{c}-0,001192 \\
(-2,7288)^{* * * *}\end{array}$ \\
\hline END & $\begin{array}{c}-0,059783 \\
(-17,739)^{* * *}\end{array}$ & $\begin{array}{c}-0,042928 \\
(-19,225)^{* * *}\end{array}$ & $\begin{array}{c}-0,034931 \\
(-19,969)^{* * *}\end{array}$ & $\begin{array}{c}-0,030825 \\
(-22,420)^{* * *}\end{array}$ & $\begin{array}{c}-0,032198 \\
(-23,730)^{* * *}\end{array}$ & $\begin{array}{c}-0,030101 \\
(-9,8955)^{* * *}\end{array}$ & $\begin{array}{c}-0,025238 \\
(-12,280)^{* * *}\end{array}$ \\
\hline Bens Industriais & $\begin{array}{c}0,012030 \\
(4,52193)^{* * *}\end{array}$ & $\begin{array}{c}0,007727 \\
(4,56246)^{* * *}\end{array}$ & $\begin{array}{c}0,004887 \\
(3,35900)^{* * *}\end{array}$ & $\begin{array}{c}0,004400 \\
(4,61614)^{* * *}\end{array}$ & $\begin{array}{c}0,005639 \\
(5,71380)^{* * *}\end{array}$ & $\begin{array}{c}0,004442 \\
(3,74388)^{* * *}\end{array}$ & $\begin{array}{l}0,001530 \\
(0,85409)\end{array}$ \\
\hline Consumo cíclico & $\begin{array}{c}0,005865 \\
(2,37766)^{* *}\end{array}$ & $\begin{array}{c}0,003304 \\
(1,92114)^{*}\end{array}$ & $\begin{array}{l}0,001642 \\
(1,16138)\end{array}$ & $\begin{array}{c}0,001755 \\
(1,72176)^{*}\end{array}$ & $\begin{array}{c}0,004796 \\
(4,49305)^{* * *}\end{array}$ & $\begin{array}{c}0,005937 \\
(4,34961)^{* * *}\end{array}$ & $\begin{array}{c}0,006110 \\
(3,15325)^{* * *}\end{array}$ \\
\hline $\begin{array}{l}\text { Consumo não } \\
\text { cíclico }\end{array}$ & 0,006950 & 0,004151 & 0,000399 & $-0,000286$ & 0,002727 & 0,008614 & 0,016070 \\
\hline Financeiro e outros & $\begin{array}{c}(2,50344)^{* *} \\
-0,001722 \\
(-0,7894)\end{array}$ & $\begin{array}{c}(2,44977)^{* *} \\
-0,000772 \\
(-0,4628)\end{array}$ & $\begin{array}{c}(0,27581) \\
-0,003432 \\
(-2,2249)^{* *}\end{array}$ & $\begin{array}{c}(-0,2423) \\
-0,004089 \\
(-3,2487)^{* * *}\end{array}$ & $\begin{array}{l}(1,39090) \\
0,000371 \\
(0,28077)\end{array}$ & $\begin{array}{c}(4,61507)^{* * *} \\
-0,000751 \\
(-0,5815)\end{array}$ & $\begin{array}{c}(5,76713)^{* * *} \\
0,003716 \\
(1,39748)\end{array}$ \\
\hline Materiais básicos & $-0,004017$ & $-0,003119$ & $-0,003829$ & $-0,003525$ & $-0,001926$ & $-0,001528$ & 0,000463 \\
\hline Utilidade pública & $\begin{array}{c}(-1,3807) \\
0,007089 \\
(3,62575)^{* * *} \\
\end{array}$ & $\begin{array}{c}(-2,1557)^{* *} \\
0,004293 \\
(2,95226)^{* * *} \\
\end{array}$ & $\begin{array}{c}(-2,6678)^{* * *} \\
0,002100 \\
(1,65018)^{*}\end{array}$ & $\begin{array}{c}(-3,2944)^{* * *} \\
0,000005 \\
(0,00614) \\
\end{array}$ & $\begin{array}{l}(-1,7601)^{*} \\
0,001582 \\
(1,59615) \\
\end{array}$ & $\begin{array}{c}(-1,1279) \\
0,002377 \\
(1,91850)^{*} \\
\end{array}$ & $\begin{array}{c}(0,21192) \\
0,004120 \\
(2,16466)^{* *} \\
\end{array}$ \\
\hline $\begin{array}{l}\text { Intervalos no } \\
\text { tempo } \\
\text { Empresas } \\
\text { Observações }\end{array}$ & $\begin{array}{c}35 \\
124 \\
4340\end{array}$ & & & & & & \\
\hline \multirow[t]{2}{*}{ Wald } & \multicolumn{7}{|c|}{$W=445,37$ com $p$-valor 0,0000} \\
\hline & & & & ROA & & & \\
\hline Quantis & 0.125 & 0.250 & 0.375 & 0.500 & 0.625 & 0.750 & 0.875 \\
\hline Constante & $\begin{array}{c}-0,039245 \\
(-5,5800)^{* * *}\end{array}$ & $\begin{array}{l}-0,006903 \\
(-1,7235)^{*}\end{array}$ & $\begin{array}{c}0,012866 \\
(4,00813)^{* * * *}\end{array}$ & $\begin{array}{c}0,020583 \\
(6,79780)^{* * *}\end{array}$ & $\begin{array}{c}0,033184 \\
(8,22475)^{* * *}\end{array}$ & $\begin{array}{c}0,051003 \\
(9,72523)^{* * *}\end{array}$ & $\begin{array}{c}0,080716 \\
(12,5736)^{* * * *}\end{array}$ \\
\hline
\end{tabular}




\begin{tabular}{|c|c|c|c|c|c|c|c|}
\hline $\mathrm{FCL}(2)$ & $\begin{array}{l}0,004741 \\
(0,88087)\end{array}$ & $\begin{array}{c}0,007691 \\
(1,62485)^{*}\end{array}$ & $\begin{array}{c}0,005948 \\
(2,00547)^{* *}\end{array}$ & $\begin{array}{c}0,005047 \\
(1,99884)^{* *}\end{array}$ & $\begin{array}{c}0,004048 \\
(3,13038)^{* * *}\end{array}$ & $\begin{array}{c}0,003488 \\
(16,2268)^{* * *}\end{array}$ & $\begin{array}{c}0,003143 \\
(4,22450)^{* * *}\end{array}$ \\
\hline \multirow[t]{2}{*}{$\mathrm{FCL}(2)(-1)$} & 0,000303 & 0,000547 & 0,000594 & 0,000579 & 0,000320 & 0,000137 & $-0,000128$ \\
\hline & $(0,55727)$ & $(1,18315)$ & $(0,34250)$ & $(1,77970)^{*}$ & $(1,63455)^{*}$ & $(2,01440)^{* *}$ & $(-1,0344)$ \\
\hline \multirow[t]{2}{*}{ TAM } & 0,003739 & 0,001868 & 0,000811 & 0,000434 & $-0,000080$ & $-0,000836$ & $-0,002413$ \\
\hline & $(9,67842)^{* * *}$ & $(7,56730)^{* * *}$ & $(3,88054)^{* * *}$ & $(2,00624)^{* *}$ & $(-0,3384)$ & $(-2,7504)^{* * *}$ & $(-6,2340)^{* * *}$ \\
\hline \multirow[t]{2}{*}{ END } & $-0,057131$ & $-0,041390$ & $-0,034117$ & $-0,031469$ & $-0,031128$ & $-0,031593$ & $-0,026526$ \\
\hline & $(-16,288)^{* * *}$ & $(-11,258)^{* * *}$ & $(-14,067)^{* * *}$ & $(-10,085)^{* * *}$ & $(-20,666)^{* * *}$ & $(-19,371)^{* * *}$ & $(-10,242)^{* * *}$ \\
\hline \multirow[t]{2}{*}{ Bens Industriais } & 0,009772 & 0,004893 & 0,001215 & 0,001910 & 0,001085 & $-0,000987$ & $-0,004686$ \\
\hline & $(3,63433)^{* * *}$ & $(2,93418)^{* * *}$ & $(1,08334)$ & $(1,78290)^{*}$ & $(0,84180)$ & $(-0,6417)$ & $(-3,6219)^{* * *}$ \\
\hline \multirow[t]{2}{*}{ Consumo cíclico } & 0,005427 & 0,000692 & $-0,001379$ & $-0,000086$ & 0,0000337 & $-0,000882$ & 0,000120 \\
\hline & $(2,16028)^{* *}$ & $(0,42632)$ & $(-1,3356)$ & $(-0,0903)$ & $(0,02719)$ & $(-0,5740)$ & $(0,08116)$ \\
\hline \multirow{2}{*}{$\begin{array}{l}\text { Consumo não } \\
\text { cíclico }\end{array}$} & 0,006492 & 0,00142 & $-0,002360$ & $-0,002226$ & $-0,001558$ & 0,003538 & 0,012498 \\
\hline & $(2,86344)^{* * *}$ & $(0,98162)$ & $(-2,2393)^{* *}$ & $(-2,0160)^{* *}$ & $(-0,9026)$ & $(1,77030)^{*}$ & $(4,87364)^{* * *}$ \\
\hline \multirow[t]{2}{*}{ Financeiro e outros } & $-0,002286$ & $-0,001125$ & $-0,003592$ & $-0,003385$ & $-0,005005$ & $-0,007350$ & $-0,004559$ \\
\hline & $(-0,8178)$ & $(-0,5218)$ & $(-2,8618)^{* * *}$ & $(-2,9968)^{* * *}$ & $(-3,4414)^{* * *}$ & $(-3,8787)^{* * *}$ & $(-0,7004)$ \\
\hline \multirow[t]{2}{*}{ Materiais básicos } & $-0,003100$ & $-0,004613$ & $-0,006190$ & $-0,005756$ & $-0,006677$ & $-0,007295$ & $-0,006408$ \\
\hline & $(-1,1325)$ & $(-3,4056)^{* * *}$ & $(-5,8988)^{* * *}$ & $(-6,0602)^{* * *}$ & $(-5,1696)^{* * *}$ & $(-4,3485)^{* * *}$ & $(-3,3955)^{* * *}$ \\
\hline \multirow[t]{2}{*}{ Utilidade pública } & 0,010814 & 0,00434 & 0,001448 & 0,001184 & 0,001086 & 0,001184 & 0,002074 \\
\hline & $(5,43194)^{* * *}$ & $(3,09282)^{* * *}$ & $(1,54617)$ & $(1,27944)$ & $(0,88660)$ & $(0,78392)$ & $(1,32694)$ \\
\hline \multicolumn{8}{|c|}{$\begin{array}{ll}\text { Intervalos no } & 35 \\
\text { tempo } & 35\end{array}$} \\
\hline Empresas & \multicolumn{7}{|c|}{$\begin{array}{l}\text { Empresas } \\
\text { Empo }\end{array}$} \\
\hline \multicolumn{8}{|l|}{ Observações } \\
\hline Wald & \multicolumn{7}{|c|}{$\mathrm{W}=572,16$ com $\mathrm{p}$-valor 0,0000} \\
\hline
\end{tabular}


A partir da Tabela 6 observa-se que o $\mathrm{FCL}(1)$ apresentou relação positiva e relevância estatística em quase todos os quantis, com exceção do quantil mais baixo $(0,125)$, que não mostrou significância. $\mathrm{O} F C L(1)$ mostrou-se significante e o $\mathrm{FCL}(1)(-1)$ não, como não estimação via MQO. Ficou evidente também que os coeficientes do $\mathrm{FCL}(1)$ e $\mathrm{FCL}(1)(-1)$ tem maior influência sobre o ROA e dependência positiva nos dois maiores quantis $(0,750$ e 0,825$)$, mesmo o $\mathrm{FCL}(1)(-1)$ não sendo estatisticamente significante. Os resultados encontrados são contrários à Teoria do Free Cash Flow, visto que se esperavam associações negativas entre a variável dependente $(\mathrm{ROA})$ e as variáveis de interesse $[\mathrm{FCL}(1)$ e $\mathrm{FCL}(1)(-1)]$. Além do mais, a variável END evidenciou relação negativa e significativa a $1 \%$ em todos os quantis com a variável ROA, com o coeficiente crescente ao longo dos quantis, ou seja, quanto maior o ROA menor o END.

O FCL(2) manifestou coeficientes positivos com o ROA em todos os quantis da Tabela 10. Somente o primeiro quantil $(0,125)$ não expressou significância estatística. Para o $F C L(2)(-1)$, os quantis $0,500,0,625$ e 0,750 foram significativos e positivos. Ao contrário dos resultados via MQO que expressaram relação negativa e sem significância. O quantil mais extremo $(0,875)$ apresentou coeficiente negativo, mas sem significância, que resgata a Teoria do Free Cash Flow de Jensen (1986a, 1986b, 1988) em que extremos seriam prejudiciais ao desempenho econômico. O END mais uma vez, como no caso do ROA com FCL(1) [regressão quantílica], evidenciou relação negativa e significativa a $1 \%$ em todos os quantis e com o coeficiente crescente ao longo dos quantis, ou seja, quanto maior o ROA menor seria o endividamento da empresa.

$\mathrm{Na}$ Tabela 7 apresentam-se os resultados da regressão quantílica para o Market-to-Book(MB) e o q de Tobin com o FCL(1) e FCL(2). 
Tabela 7 - Estimação da relação entre o Market-to-Book (MB) e o q de Tobin com o Fluxo de Caixa Livre (1) e (2) nos diferentes quantis de 2009 a 2017

\begin{tabular}{|c|c|c|c|c|c|c|c|c|c|c|c|c|c|c|}
\hline \multirow[b]{2}{*}{ Quantis } & \multicolumn{7}{|c|}{ MB } & \multicolumn{7}{|c|}{$q$ de Tobin } \\
\hline & 0.125 & 0.250 & 0.375 & 0.500 & 0.625 & 0.750 & 0.875 & 0.125 & 0.250 & 0.375 & 0.500 & 0.625 & 0.750 & 0.875 \\
\hline \multirow[t]{2}{*}{ Constante } & $-0,377753$ & $-0,682027$ & $-0,548750$ & $-0,491313$ & $-0,345070$ & $-0,494751$ & 1,888009 & $-0,331748$ & 0,019298 & $-0,006703$ & 0,040084 & 0,134088 & 0,313599 & 1,083885 \\
\hline & $(-2,0201)^{* *}$ & $(-3,3199)^{* * *}$ & $(-2,1618)^{* *}$ & $(-1,6089)^{*}$ & $(-0,9308)$ & $(-0,8595)$ & $(2,71518)^{* * *}$ & $(-2,5415)^{* *}$ & $(0,11935)$ & $(-0,0563)$ & $(0,32032)$ & $(0,94427)$ & $(1,88378)^{*}$ & $(3,28332)^{* * *}$ \\
\hline \multirow[t]{2}{*}{$\mathrm{FCL}(1)$} & $-1,208834$ & $-1,765527$ & $-2,130884$ & $-2,412858$ & $-2,377262$ & $-3,663229$ & $-4,999053$ & $-0,812498$ & $-1,137573$ & $-0,752877$ & $-0,727835$ & $-1,019791$ & $-0,794283$ & $-2,06282$ \\
\hline & $(-2,4596)^{* *}$ & $(-3,4881)^{* * *}$ & $(-3,4997)^{* * *}$ & $(-4,7825)^{* * *}$ & $(-3,1652)^{* * *}$ & $(-4,0250)^{* * *}$ & $(-2,1800)^{* *}$ & $(-3,6164)^{* * *}$ & $(-4,3937)^{* * *}$ & $(-3,5537)^{* * *}$ & $(-2,8003)^{* * *}$ & $(-3,3983)^{* * *}$ & $(-2,1267)^{* *}$ & $(-3,2621)^{* * *}$ \\
\hline \multirow[t]{2}{*}{$\mathrm{FCL}(1)(-1)$} & $-0,786066$ & $-1,757742$ & $-2,055938$ & $-1,965597$ & $-2,010388$ & $-1,482336$ & $-2,844068$ & $-0,597148$ & $-0,867661$ & $-0,416549$ & $-0,549474$ & $-0,442996$ & $-0,660871$ & $-0,039818$ \\
\hline & $(-1,3018)$ & $(-2,9478)^{* * *}$ & $(-3,3491)^{* * *}$ & $(-3,5853)^{* * *}$ & $(-4,0475)^{* * *}$ & $(-1,4403)$ & $(-1,1607)$ & $(-2,4174)^{* *}$ & $(-2,8241)^{* * *}$ & $(-1,6134)^{*}$ & $(-1,8976)^{*}$ & $(-1,7055)^{*}$ & $(-1,4141)$ & $(-0,0705)$ \\
\hline \multirow[t]{2}{*}{ TAM } & 0,070891 & 0,101718 & 0,113931 & 0,135777 & 0,147285 & 0,194781 & 0,031741 & 0,013918 & 0,019574 & 0,030026 & 0,034777 & 0,038206 & 0,036009 & 0,030673 \\
\hline & $(7,34649)^{* * *}$ & $(8,71021)^{* * *}$ & $(7,62160)^{* * *}$ & $(7,37331)^{* * *}$ & $(6,13673)^{* * *}$ & $(4,00506)^{* * *}$ & $(0,62816)$ & $(1,45422)$ & $(2,60827)^{* * *}$ & $(3,90672)^{* * *}$ & $(4,83434)^{* * *}$ & $(4,72988)^{* * *}$ & $(3,85796)^{* * *}$ & $(1,73898)^{*}$ \\
\hline \multirow[t]{2}{*}{ END } & $-0,489764$ & $-0,366365$ & $-0,434085$ & $-0,327444$ & $-0,208931$ & 0,418969 & 3,468038 & 0,378595 & 0,437551 & 0,467505 & 0,454532 & 0,461372 & 0,522264 & 0,543617 \\
\hline & $(-7,3577)^{* * *}$ & $(-10,608)^{* * *}$ & $(-10,093)^{* * *}$ & $(-2,7014)^{* * *}$ & $(-4,8975)^{* * *}$ & $(1,04518)$ & $(3,90231)^{* * *}$ & $(4,07339)^{* * *}$ & $(5,79933)^{* * *}$ & $(7,66663)^{* * *}$ & $(8,78127)^{* * *}$ & $(8,88365)^{* * *}$ & $(22,9113)^{* * * *}$ & $(7,54334)^{* * *}$ \\
\hline \multirow[t]{2}{*}{ Bens Industriais } & 0,104391 & 0,230117 & 0,264295 & 0,127678 & 0,144513 & $-0,074205$ & $-0,442068$ & 0,255894 & $-0,057495$ & $-0,065871$ & $-0,041855$ & $-0,055534$ & $-0,092738$ & $-0,423522$ \\
\hline & $(1,40442)$ & $(3,04228)^{* * *}$ & $(2,91555)^{* * *}$ & $(1,16961)$ & $(0,99737)$ & $(-0,1880)$ & $(-1,7537)^{*}$ & $(6,03538)^{* * *}$ & $(-1,1438)$ & $(-1,6429)^{*}$ & $(-1,0654)$ & $(-1,1317)$ & $(-1,6057)^{*}$ & $(-3,5692)^{* * *}$ \\
\hline \multirow[t]{2}{*}{ Consumo cíclico } & 0,003515 & 0,007942 & 0,039014 & 0,040306 & 0,21092 & 0,054266 & 0,673417 & 0,017604 & $-0,279124$ & $-0,242021$ & $-0,079574$ & 0,119761 & 0,258746 & 0,033306 \\
\hline & $(0,05692)$ & $(0,11105)$ & $(0,41655)$ & $(0,35428)$ & $(1,44674)$ & $(0,13296)$ & $(2,59190)^{* * *}$ & $(0,44265)$ & $(-4,8040)^{* * *}$ & $(-5,7205)^{* * * *}$ & $(-1,3639)$ & $(2,10095)^{* *}$ & $(4,38937)^{* * *}$ & $(0,29942)$ \\
\hline \multirow[t]{2}{*}{$\begin{array}{l}\text { Consumo não } \\
\text { cíclico }\end{array}$} & 0,320232 & 0,368897 & 0,527710 & 0,544026 & 1,113026 & 1,352106 & 4,200120 & 0,383595 & 0,093071 & 0,159973 & 0,198422 & 0,371246 & 0,891261 & 1,813728 \\
\hline & $(4,14543)^{* * *}$ & $(3,99021)^{* * *}$ & $(3,9691)^{* * *}$ & $(3,07708)^{* * *}$ & $(4,15028)^{* * *}$ & $(2,08284)^{* *}$ & $(6,28974)^{* * *}$ & $(8,07460)^{* * *}$ & $(1,32910)$ & $(3,28196)^{* * *}$ & $(3,98329)^{* * *}$ & $(3,21453)^{* * *}$ & $(4,72557)^{* * *}$ & $(8,48773)^{* * *}$ \\
\hline \multirow[t]{2}{*}{ Financeiro e outros } & 0,085469 & 0,110244 & $-0,044062$ & $-0,325536$ & $-0,47412$ & $-1,133082$ & $-1,267242$ & 0,22699 & $-0,000658$ & 0,05569 & 0,10063 & 0,089212 & 0,084781 & $-0,288102$ \\
\hline & $(0,87845)$ & $(1,53781)$ & $(-0,4935)$ & $(-2,9879)^{* * *}$ & $(-2,9899)^{* * *}$ & $(-2,7142)^{* * *}$ & $(-3,1069)^{* * *}$ & $(3,45171)^{* * * *}$ & $(-0,0080)$ & $(0,92470)$ & $(2,02431)^{* *}$ & $(1,58651)$ & $(1,45171)$ & $(-1,9940)^{* *}$ \\
\hline \multirow[t]{2}{*}{ Materiais básicos } & $-0,038781$ & $-0,062927$ & $-0,177956$ & $-0,467332$ & $-0,670384$ & $-1,343265$ & $-1,961273$ & 0,174413 & $-0,198489$ & $-0,213472$ & $-0,224744$ & $-0,287413$ & $-0,347208$ & $-0,886633$ \\
\hline & $(-0,6343)$ & $(-0,9658)$ & $(-2,2151)^{* *}$ & $(-4,6316)^{* * *}$ & $(-5,1006)^{* * *}$ & $(-3,3662)^{* * *}$ & $(-5,7536)^{* * *}$ & $(4,01897)^{* * *}$ & $(-3,9166)^{* * *}$ & $(-4,7570)^{* * *}$ & $(-6,5738)^{* * *}$ & $(-6,9996)^{* * *}$ & $(-7,1568)^{* * *}$ & $(-9,3437)^{* * *}$ \\
\hline \multirow[t]{2}{*}{ Utilidade pública } & $-0,078459$ & $-0,085151$ & $-0,234774$ & $-0,481511$ & $-0,624392$ & $-1,278899$ & $-2,037243$ & 0,434029 & 0,026108 & $-0,019525$ & $-0,070699$ & $-0,168706$ & $-0,26234$ & $-0,774208$ \\
\hline & $(-1,3026)$ & $(-1,3410)$ & $(-2,9319)^{* * *}$ & $(-4,7584)^{* * *}$ & $(-4,3979)^{* * *}$ & $(-3,2686)^{* * *}$ & $(-8,4085)^{* * * *}$ & $(8,69442)^{* * * *}$ & $(0,60083)$ & $(-0,4800)$ & $(-2,2855)^{* *}$ & $(-4,3992) * * *$ & $(-5,7809)^{* * *}$ & $(-7,9780)^{* * *}$ \\
\hline Intervalos no tempo & 35 & & & & & & & 35 & & & & & & \\
\hline Empresas & 97 & & & & & & & 99 & & & & & & \\
\hline Observaçöes & 3395 & & & & & & & 3465 & & & & & & \\
\hline \multirow[t]{2}{*}{ Wald } & \multicolumn{3}{|c|}{$W=1118,22$ com $p$-valor 0,0000} & \multicolumn{11}{|c|}{$W=1293,78$ com $p$-valor 0,0000} \\
\hline & \multicolumn{7}{|c|}{ MB } & \multicolumn{7}{|c|}{$q$ de Tobin } \\
\hline Quantis & 0.125 & 0.250 & 0.375 & 0.500 & 0.625 & 0.750 & 0.875 & 0.125 & 0.250 & 0.375 & 0.500 & 0.625 & 0.750 & 0.875 \\
\hline \multirow[t]{2}{*}{ Constante } & $-0,106696$ & 0,258046 & 0,608340 & 1,321042 & 1,951441 & 3,172848 & 6,491476 & $-0,592498$ & 0,065754 & 0,219685 & 0,491324 & 0,793717 & 1,535434 & 3,829168 \\
\hline & $(-0,6271)$ & $(1,36429)$ & $(2,70434)^{* * *}$ & $(4,60789)^{* * *}$ & $(5,63137)^{* * *}$ & $(5,50733)^{* * *}$ & $(8,09315)^{* * * *}$ & $(-5,8175)^{* * *}$ & $(0,52065)$ & $(1,95206)^{*}$ & $(3,59332)^{* * *}$ & $(5,72077)^{* * *}$ & $(5,46697)^{* * * *}$ & $(9,18345)^{* * *}$ \\
\hline
\end{tabular}




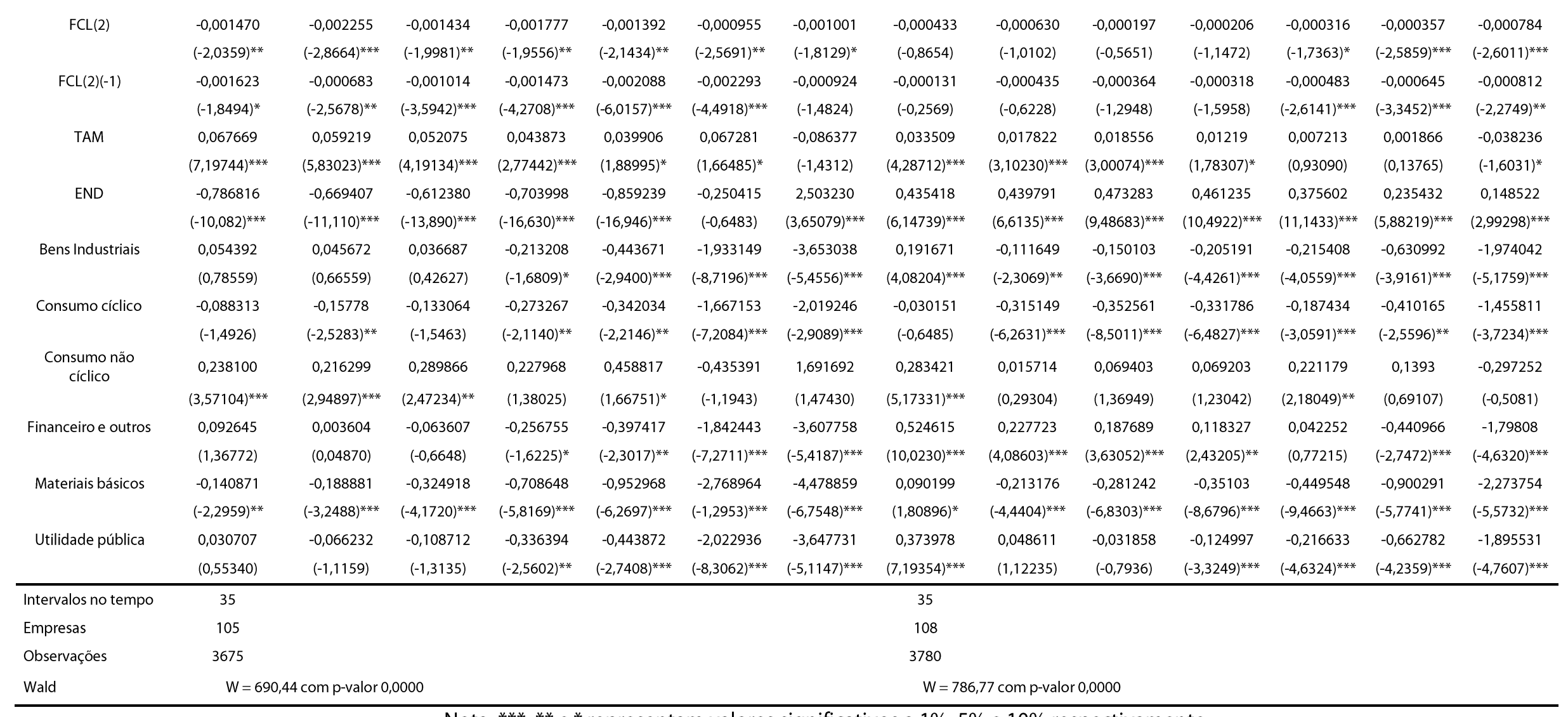

Nota: $* * * * * *{ }^{*}$ representam valores significativos a $1 \%, 5 \%$ e $10 \%$ respectivamente.

Fonte: Elaborada a partir dos dados da pesquisa (2018). 
$\mathrm{Na}$ Tabela 7 fica evidente que há uma relação negativa e significativa entre o $\mathrm{MB}$ e o $\mathrm{FCL}(1)$, que não ocorreu de forma clara na estimação via MQO. A intensidade dessa relação (coeficiente) fica mais forte negativamente na proporção crescente dos quantis, o que corrobora o pressuposto de que níveis altos de $\mathrm{FCL}$ são mais desvantajosos para o desempenho econômico. O FCL(1)(-1) foi significante em quatro dos sete quantis, sendo o quantil mais extremo $(0,875)$ com maior expressividade negativa sobre a variável dependente $(\mathrm{MB})$, podendo indicar também que o $\mathrm{FCL}$ em excesso influencia o desempenho econômico de forma negativa. A variável categórica Consumo não cíclico mostrou significância estatística em todos os quantis, ou seja, este setor tem grande influência sobre o ROA.

O FCL(2) e o $\mathrm{FCL}(2)(-1)$ evidenciaram relação negativa e significativa com o $\mathrm{MB}$ em quase todos os quantis, com exceção do quantil 0,875 do $\mathrm{FCL}(2)(-1)$, que não apresentou significância. Deste modo, é possível inferir que o $\mathrm{FCL}$ em qualquer quantia afeta o MB negativamente, de acordo com a relação esperada das variáveis pela literatura, exposto na Tabela 1. Além do mais, o setor Materiais básicos se mostrou ser significante em qualquer quantil.

Na relação do $\mathrm{FCL}(1)$ e do $\mathrm{FCL}(1)(-1)$ com $q$ de Tobin, evidenciou-se relação negativa e significativa em quase todos os quantis da Tabela 7, com exceção dos quantis 0,750 e 0,875 do $\operatorname{FCL}(1)(-1)$, que não apresentaram significância. A associação negativa encontrada está de acordo com o apontado pela literatura (Tabela 1) e os achados são reforçados pelos sinais da estimação via MQO. A variável END revelou relacionarse positivamente ao $q$ de Tobin com alta significância estatística (1\%) em todos os quantis.

Assim como na estimação via regressão quantílica do $q$ de Tobin com o FCL(1), a relação do $q$ de Tobin com o $\mathrm{FCL}(2)$ e o $\mathrm{FCL}(2)(-1)$ apresentam associações negativas nos coeficientes. Contudo a significância estatística ficou restrita aos quantis $0,625,0,750$ e 0,875, ou seja, nas empresas com os maiores $q$ de Tobin, 0 FCL passa a ser mais expressivo (de forma negativa) e significativo. As evidências apontadas pela estimação via MQO e via regressão quantílica reforçam a relação negativa apontada pela literatura (Tabela 1) entre FCL e indicadores de desempenho. O setor Bens industriais destacou-se por ter forte poder de explicação no modelo em questão. A variável END, assim como na regressão quantílica do $q$ de Tobin com o FCL(1), manifestou relacionar-se positivamente ao $q$ de Tobin com alta significância estatística (1\%) em todos os quantis. É importante salientar que não foram encontrados estudos semelhantes, mesmo no contexto internacional, que relacionassem a Teoria do Free Cash Flow utilizando regressão quantílica, para um cotejamento dos resultados satisfatório.

\subsection{Interpretação dos resultados}

Para os IDE via MQO, o ROA foi a única variável dependente que mostrou coeficientes positivos com FCL(1) e FCL(1)(-1) nos três modelos em painel, contrário a relação esperada pela $\mathrm{H}_{1}$ (O Fluxo de Caixa Livre relaciona-se negativamente com os Indicadores de Desempenho Econômico). Oq de Tobin exclusivamente exibiu coeficientes negativos com $\mathrm{FCL}(1)$ e $\mathrm{FCL}(1)(-1)$ nos três modelos em painel, de acordo com a relação esperada pela $\mathrm{H}_{1}$. Assim, sob tais condições de análise, o ROA apresentou a evidência mais robusta de relação contrária ao esperado pela literatura (Tabela 1).

Os resultados para o $q$ de Tobin, via MQO, tanto para o $\mathrm{FCL}(1)$ quanto para o $\mathrm{FCL}(2)$, foram os mais contraditórios com base em estudos anteriores de Chung, Firth e Kim (2005), Wang (2010), Mansourlakoraj e Sepasi (2015) e Najmi, Sarraf e Darabi (2015) e Kadioglu, Kilic e Yilmaz (2017), visto que os coeficientes e significâncias estatísticas foram distintos.

Comparando os resultados dos Fluxos de Caixas Livres (1) e (2) via MQO, observa-se o FCL(1) demonstrou mais coeficientes ordenados em comparação com o FCL(2),visto que o FCL(1) expressou uma relação unicamente positiva com o ROA e exclusivamente negativa com o $q$ de Tobin. Assim, não se desconsidera a possibilidade do FCL influenciar os IDE das companhias abertas brasileiras, tanto de forma positiva quanto negativa, dependendo de quais as variáveis são testadas. Deste modo, também não foi possível rejeitar $\mathrm{a} \mathrm{H}_{1}$.

A hipótese apontada por Jensen (1986a, 1986b, 1988) de que o FCL excessivo é prejudicial para as companhias também não pode ser rejeitada na empresas listadas na $[B]^{3}$. Pelo fato do produto da estimação 
via regressão quantílica do $\mathrm{MB}$ com $\mathrm{FCL}(1)$, em que a vulnerabilidade negativa e significativa do $\mathrm{FCL}(1)$ cresce na proporção dos quantis.

Ademais, um resultado peculiar observado na Tabela 6, na qual o $\mathrm{FCL}(2)(-1)$ tem uma associação positiva com o ROA até o quantil 0,750 , ponto de inflexão. No quantil seguinte $(0,875)$, a relação que vinha sempre sendo positiva torna-se negativa, que supostamente poderia retratar o momento em que o FCL se torna excedente.

Sendo assim, a resposta para o questionamento de como o Fluxo de Caixa Livre influencia o desempenho econômico das companhias abertas brasileiras é em alguns dos casos o $F C L$ afetou o desempenho de forma positiva, em outros de forma negativa, ou ambos. Embora, destaca-se que para a estimação via regressão quantílica o $\mathrm{FCL}(1)$ e o $\mathrm{FCL}(2)$ relacionaram-se unicamente de forma negativa com o MB e com o q de Tobin.

\section{CONSIDERAÇÕES FINAIS}

Essa pesquisa teve por objetivo investigar qual é a influência do FCL nos IDE das companhias abertas brasileiras da [B] $]^{3}$. Os estudos de Hong, Shuting e Meng (2012), Mansourlakoraj e Sepasi (2015), Moussavi et al. (2015), Najmi, Sarraf e Darabi (2015), Hau (2017) e Kadioglu, Kilic e Yilmaz (2017) apresentam resultados muito variados, assim, a métrica do $\mathrm{FCL}$ demanda atenção dos usuários, pois, dependendo da medida utilizada, os resultados podem ser divergentes como foi observado nesta pesquisa. Observou-se que o $F C L(1)$ e $F C L(2)$ apresentaram estatísticas diferentes entre si, o que corrobora o fato dessa medida ser arbitrária e ao mesmo tempo subjetiva.

Com as evidências encontradas não se desconsidera a possibilidade de o FCL influenciar os IDE das companhias abertas brasileiras, visto que os indícios mostram que algumas estimações expõem os sinais dos coeficientes em conformidade com o projetado preliminarmente, outras não, sendo relativo para cada variável. Não obstante, os achados das regressões quantílicas apontam problemas de agência nas companhias listadas na $[B]^{3}$, pois sua sensibilidade aumenta nos maiores quantis. Consequentemente, a Teoria do Free Cash Flow de Jensen (1986a, 1986b, 1988) não pode ser rejeitada no mercado brasileiro.

As evidências empíricas também são importantes para os investidores e executivos da empresa, a fim de estabelecer políticas de gestão mais eficazes que minimizem os custo de agência. Além disso, profissionais do mercado têm grande interesse em entender e mensurar Fluxos de Caixa Livres futuros e compará-los entre companhias e setores. Percebem-no como uma métrica complementar na análise de investimentos. Assim, é esperado que o tema possa despertar interesse dos gestores, acionistas, usuários das demonstrações contábeis e estudantes em geral, além de que a temática tem recebido pouca atenção do meio acadêmico brasileiro.

Cabe ressaltar que esta pesquisa apresentou uma limitação principalmente no escopo da base de dados da Economática ${ }^{\circ}$. As informações necessárias continham muitos dados faltantes (missing data), o que comprometeu a abrangência dos anos do estudo e do número de companhias. Assim, as estimações dos modelos econométricos limitaram-se àquelas empresas que apresentaram dados completos de 2009 a 2017. Além disso, o FCL permanece com característica subjetiva visto que a literatura não chegou a um consenso como única forma de mensuração.

Para pesquisas futuras sugere-se verificar qual o modelo de $\mathrm{FCL}$ mais utilizado pelos investidores e analistas. Identificar outras maneiras de estimar o FCL. É possível estimar o mesmo modelo utilizando outras variáveis dependentes. Também há a possibilidade de utilizar o FCL como variável dependente. Ademais, existe a viabilidade de relacionar o $\mathrm{FCL}$ com pagamento de dividendos ou oportunidades de crescimento. Tento como objetivo verificar a Teoria do Free Cash Flow em que FCL em excesso estaria correlacionado negativamente com o pagamento de dividendos e com as oportunidades de crescimento. 


\section{REFERÊNCIAS}

ALMEIDA, J. E. F.; SOUSA, A. F.; RODRIGUES, A. Fluxo de caixa e accruals: objetividade versus subjetividade no índice market-to-book das companhias abertas brasileiras. Sociedade, Contabilidade e Gestão, Rio de Janeiro, v. 4, n. 1, p. 106-117, 2009. Disponível em: http://www.atena.org.br/revista/ojs-2.2.306/index.php/ufrj/article/viewArticle/473. Acesso em: 26 ago. 2020.

ATAÜNAL, L.; AYBARS, A. Is excess free cash flow over-invested? Evidence from Borsa Istanbul. Marmara Üniversitesi I ktisadi vê İdari Bilimler Dergisi, [S.I.], v. 39, n. 1, p. 1-17, June 2017. Disponível em: http://dspace.marmara.edu.tr/xmlui/bitstream/handle/11424/6190/10.14780-muiibd.329721328040.pdf?sequence=1\&isAllowed=y. Acesso em: 26 ago. 2020.

BASTOS, D. D.; NAKAMURA, W. T.; BASSO, L. F. C. Determinantes da estrutura de capital das companhias abertas na América Latina: um estudo empírico considerando fatores macroeconômicos e institucionais. Revista de Administração Mackenzie (RAM), São Paulo, v. 10, n. 6, p. 47-77, nov./dez. 2009. Disponível em: https://www.scielo.br/pdf/ram/v10n6/05.pdf. Acesso em: 26 ago. 2020.

BHANDARI, S. B.; ADAMS, M. T. On the definition, measurement, and use of the free cash flow concept in financial reporting and analysis: a review and recommendations. Journal of Accounting and Finance, [S.I.], v. 17, n. 1, p. 11-19, 2017. Disponível em: http://www.na-businesspress.com/JAF/BhandariSB_Web17_1_.pdf. Acesso em: 16 jul. 2020.

BREALEY, R. A.; MYERS, S. C.; ALLEN, F. Princípios de finanças corporativas. 8. ed. São Paulo: McGraw-Hill, 2008.

BRIGHAM, E. F.; EHRHARDT, M. C. Administração financeira: teoria e prática. 3. ed. São Paulo: Cengage Learning, 2016.

CAl, J. Investor protections, financial development and corporate investment efficiency. Journal of Applied Finance and Banking, London, v. 4, n. 6, p. 59-92, 2014. Disponível em:

https://www.scienpress.com/journal_focus.asp?main_id=56\&Sub_id=IV\&lssue=1328. Acesso em: 26 ago. 2020.

CHEN, X.; SUN, Y.; XU, X. Free cash flow, over-investment and corporate governance in China. Pacific-Basin Finance Journal, [S.I.], v. 37, p. 81-103, 2016. Disponível em: https://www.sciencedirect.com/science/article/pii/S0927538X15300019. Acesso em: 16 jul. 2020.

CHUNG, R.; FIRTH, M.; KIM, J. FCF agency costs, earnings management, and investor monitoring. Corporate Ownership \& Control, Sumy, v. 2, n. 4, p. 51-61, Summer 2005. Disponível em: http://www.virtusinterpress.org/IMG/pdf/cocv2i4p4.pdf. Acesso em: 26 ago. 2020.

DAMODARAN, A. Finanças corporativas aplicadas. Porto Alegre: Bookman, 2002.

DAMODARAN, A. Finanças corporativas: teoria e prática. 2. ed. Porto Alegre: Bookman, 2004.

DIAL, J.; MURPHY, K. J. Incentives, downsizing, and value creation at general dynamics. Journal of Financial Economics, Lausanne, v. 37, n. 3, p. 261-314, Mar. 1995. Disponível em:

https://www.sciencedirect.com/science/article/pii/0304405X94008039. Acesso em: 26 ago. 2020.

DOUKAS, J. A. Overinvestment, Tobin's $q$ and gains from foreign acquisitions. Journal of Banking \& Finance, Amsterdam, v. 19, n. 7, p. 1285-1303, 1995. Disponível em:

https://www.sciencedirect.com/science/article/pii/037842669400117L. Acesso em: 26 ago. 2020.

FOX, I.; MARCUS, A. The causes and consequences of leveraged management buyouts. Academy of Management Review, Ada, v. 17, n. 1, p. 62-85, Jan. 1992. Disponível em: https://www.jstor.org/stable/258648. Acesso em: 26 ago. 2020.

GUL, F. A.; TSUI, J. S. L. A test of the free cash flow and debt monitoring hypotheses: evidence from audit pricing. Journal of Accounting and Economics, Amsterdam, v. 24, n. 2, p. 219-237, 1998. Disponível em: http://www.sciencedirect.com/science/article/pii/S0165410198000068. Acesso em: 26 ago. 2020.

HAIR, J. F. et al. Análise multivariada de dados. 6. ed. Porto Alegre: Bookman, 2009. 
HAU, L. L. Free cashflow and firm performance: evidence from sectoral levels for Vietnamese listed firms. International Journal of Advanced Engineering, Management and Science (IJAEMS), [S.I.], v. 3, n. 4, p. 296-300, 2017. Disponível em: https://dx.doi.org/10.24001/ijaems.3.4.2. Acesso em: 26 ago. 2020.

HONG, Z.; SHUTING, Y.; MENG, Z. Relationship between free cash flow and financial performance evidence from the listed real estate companies in China. International Proceedings of Computer Science and Information Technology (IPCSIT), [S.I.], v. 36, p. 331-335, 2012. Disponível em: http://www.ipcsit.com/vol36/064-ICIIM2012-M20017.pdf. Acesso em: 26 ago. 2020.

JENSEN, M. C. Agency cost of free cash flow, corporate finance, and takeovers. The American Economic Review, Nashville, v. 76, n. 2, p. 323-329, 1986a. Disponível em: https://www.jstor.org/stable/1818789. Acesso em: 26 ago. 2020.

JENSEN, M. C. Takeovers: their causes and consequences. The Journal of Economic Perspectives, Nashville, v. 2, n. 1, p. 21-48, 1988. Disponível em:

http://www.jstor.org/stable/1942738?seq=1\#page_scan_tab_contents. Acesso em: 26 ago. 2020.

JENSEN, M. C. The modern industrial revolution, exit, and the failure of internal control systems. The Journal of Finance, [S.I.], v. 48, n. 3, p. 831-880, July 1993. Disponível em:

https://onlinelibrary.wiley.com/doi/abs/10.1111/j.1540-6261.1993.tb04022.x. Acesso em: 26 ago. 2020.

JENSEN, M. C. The takeover controversy: analysis and evidence. Midland Corporate Finance Journal, [S.I.], v. 4, n. 2, 1986b. Disponível em: https://papers.ssrn.com/sol3/papers.cfm?abstract_id=173452. Acesso em: 26 ago. 2020.

JENSEN, M. C.; MECKLING, W. H. Theory of the firm: managerial behavior, agency costs and ownership structure. Journal of Financial Economics, Lausanne, v. 3, n. 4, p. 305-360, Oct. 1976. Disponível em: http://www.sciencedirect.com/science/article/pii/0304405X7690026X. Acesso em: 26 ago. 2020.

JIANG, X. Over-investment of free cash flow during CEO's tenure. Technology and Investment, [S.I.], v. 7, n. 3, p. 51-58, 2016. Disponível em: http://dx.doi.org/10.4236/ti.2016.73007. Acesso em: 26 ago. 2020.

KADIOGLU, E.; KILIC, S.; YILMAZ, E. A. Testing the relationship between free cash flow and company performance in Borsa Istanbul. International Business Research, [S.I.], v. 10, n. 5, p. 148-158, 2017. Disponível em: http://www.ccsenet.org/journal/index.php/ibr/article/view/67250. Acesso em: 26 ago. 2020.

KESTER, W. C. Capital and ownership structure: a comparison of United States and Japanese manufacturing corporations. Financial Management, Tampa, v. 15, n. 1, p. 5-16, 1986. Disponível em: https://www.jstor.org/stable/3665273. Acesso em: 26 set. 2018.

KETZ, J. E. Free cash flow and business combinations. CPA Journal, [S.I.], v. 86, n. 11, p. 48-53, Nov. 2016. Disponível em: https://www.cpajournal.com/2016/11/23/free-cash-flow-business-combinations/. Acesso em: 26 ago. 2020.

KOENKER, R.; BASSETT JUNIOR, G. Regression Quantiles. Econometrica, Chicago, v. 46, n. 1, p. 33-50, 1978. Disponível em: https://www.jstor.org/stable/1913643. Acesso em: 15 jul. 2020.

LANG, L. H. P.; STULZ, R. M.; WALKING, R. A. A test of the free cash flow hypothesis. Journal of Financial Economics, Lausanne, v. 29, n. 2, p. 315-335, Oct. 1991. Disponível em: http://www.sciencedirect.com/science/article/pii/0304405X91900055. Acesso em: 16 jul. 2020.

LEHN, K.; POULSEN, A. Free cash flow and stockholder gains in going private transactions. The Journal of Finance, [S.I.], v. 44, n. 3, p. 771-787, July 1989. Disponível em: http://www.jstor.org/stable/2328782. Acesso em: 26 ago. 2020.

MANSOURLAKORAJ, R.; SEPASI, S. Free cash flow, capital structure and the value of listed companies in Tehran Stock Exchange. International Journal of Management, Accounting and Economics, v. 2, n. 2, p. 144-148, Feb. 2015. Disponível em: http://ijmae.ir/files/accepted/154_final.pdf. Acesso em: 26 ago. 2020.

MARTELANC, R.; PASIN, R.; PEREIRA, F. Avaliação de empresas: um guia para fusões \& aquisições e private equity. São Paulo: Pearson Prentice Hall, 2010.

MILLS, J.; BIBLE, L.; MASON, R. Defining free cash flow. The CPA Journal, [S.I.], v. 72, n. 1, p. 37-41, 2002. Disponível em: http://archives.cpajournal.com/2002/0102/features/f013602.htm. Acesso em: 26 ago. 2020. 
MOUSSAVI, S. M. K. et al. The investigation of relationship between free cash flow and evaluation indicators of financial performance. International Journal of Applied Business and Economic Research (IJABER), [S.I.], v. 13, n. 6, p. 3717-3728, 2015. Disponível em: https://docplayer.net/61182485-The-investigation-ofrelationship-between-free-cash-flow-and-evaluation-indicators-of-financial-performance.html. Acesso em: 26 ago. 2020.

NAJMI, M.; SARRAF, F.; DARABI, R. Relationship between capital structure, free cash flow and performance in companies listed on Tehran Stock Exchange. European Online Journal of Natural and Social Sciences: proceedings, [S.I.], v. 4, n. 1 (s), p. 1229-1236, 2015. Disponível em: http://europeanscience.com/eojnss_proc/article/view/4331. Acesso em: 26 ago. 2020.

RICHARDSON, S. Over-investment of free cash flow. Review of Accounting Studies, [S.I.], v. 11, n. 2-3, p. 159189, 2006. Disponível em: https://link.springer.com/article/10.1007/s11142-006-9012-1. Acesso em: : 26 ago. 2020.

STOWE, J. D. et al. Equity asset valuation. Hoboken: John Wiley \& Sons, 2007.

STULZ, R. Managerial discretion and optimal financing policies. Journal of Financial Economics, Lausanne, v. 26, n. 1, p. 3-27, 1990. Disponível em:

https://www.sciencedirect.com/science/article/pii/0304405X9090011N. Acesso em: 26 ago. 2020.

WANG, G. Y. The Impacts of free cash flows and agency costs on firm performance. Journal of Service Science \& Management, [S.I.], v. 3, n. 4, p. 408-418, 2010. Disponível em: https://www.scirp.org/journal/Paperlnformation.aspx?PaperlD=3389. Acesso em: 26 ago. 2020.

ZERNI, M.; KALLUNKI, J.; NILSSON, H. The entrenchment problem, corporate governance mechanisms, and firm value. Contemporary Accounting Research, Toronto, v. 27, n. 4, p. 1169-1206, 2010. Disponível em: https://doi.org/10.1111/j.1911-3846.2010.01043.x. Acesso em: 26 ago. 2020. 